\title{
Alpha generation in portfolio management: Long-run Australian equity fund evidence
}

Australian Journal of Management

$1-34$

(C) The Author(s) 2015

Reprints and permissions: sagepub.co.uk/journalsPermissions.nav DOI: I0.I I77/03 I28962।45398I 5 aum.sagepub.com

@SAGE

\section{Scott Bennett}

Russell Investments, Sydney, NSW, Australia

\section{David R Gallagher}

Centre for International Finance and Regulation, Sydney, NSW, Australia; Macquarie Graduate School of Management, North Ryde, NSW, Australia; Capital Markets CRC Limited, Sydney, NSW, Australia; Australian School of Business, The University of New South Wales, Sydney, NSW, Australia

\section{Graham Harman}

Russell Investments, Sydney, NSW, Australia

\section{Geoffrey J Warren}

Centre for International Finance and Regulation, Sydney, NSW, Australia; Research School of Finance, Actuarial Studies and Applied Statistics, The Australian National University, Canberra, ACT, Australia

\section{Lihui Xi}

Russell Investments, Sydney, NSW, Australia; Macquarie Graduate School of Management, North Ryde, NSW, Australia; Capital Markets CRC Limited, Sydney, NSW, Australia

\begin{abstract}
This study provides the first long-run analysis of the skill of active Australian equity fund managers based on trades inferred from a market-wide database of monthly portfolio holdings over the period 1994-2009. In addition to confirming previous findings that skill exists amongst active Australian managers using a more comprehensive sample, we also deepen the understanding of this skill in two ways. First, we sharpen the identification of skill by categorizing trades. We find that alpha is concentrated in trades that are more likely to involve informed trading rather than portfolio rebalancing. Second, we investigate skill across manager types. Alpha for growthoriented managers is found to stem from selection skill, while that for value managers appears more related to characteristic exposure. We also find stronger evidence of skill amongst boutique firms relative to more institutionalized managers.
\end{abstract}

Corresponding author:

Lihui Xi, Russell Investments, Sydney, NSW 2000, Australia.

Email: yxi@russell.com

Final transcript accepted 6 May 2014 by Karen Benson (AE Finance). 


\section{JEL Classification: $\mathbf{G 2 3}$}

\section{Keywords}

Active management, alpha generation, performance evaluation, portfolio holdings, trades

\section{Introduction}

Investors, academics, industry participants and regulators have long been interested in understanding and measuring the value derived from active fund management. Studies have used various methodologies and produced equivocal results on whether fund managers exhibit superior skill and whether or not their expenses are justified. Studies that examine returns at the overall fund level typically find little evidence that the average investor benefits from active management (e.g. Barras et al., 2010; Fama and French, 2010), at least for US equities. On the other hand, studies that analyse the decisions of managers, as revealed through their portfolio holdings or trades, uncover evidence that managers possess skill (e.g. Baker et al., 2010; Daniel et al., 1997; Grinblatt and Titman, 1989, 1993; Wermers, 2000). Evidence of skill has also been found to exist amongst Australian managers (e.g. Chen et al., 2010; Gallagher and Looi, 2006; Pinnuck, 2003).

We examine the performance of net monthly trades by Australian equity managers using a unique and more comprehensive sample than those used in previous studies. Our contributions include providing clear confirmation of the existence of manager skill for a non-US market, and generating new evidence on how skill varies with manager type. We sharpen the identification of skill by categorizing trades according to their relative size and the resultant change in active position relative to the benchmark index. The intuition is that trades which are relatively large or instigate a meaningful change in active position are more likely to indicate informed trading, rather than either portfolio rebalancing (minor adjustments that do not substantially alter active position), or liquidity-related trades (made in response to fund inflows or outflows). We find that alpha is concentrated in large trades, and trades which establish or extend an active position. This not only confirms the existence of underlying skill, but also indicates that such skill may be obscured if all trades are examined unconditionally, as has been done in much of the prior literature. We also extend the understanding of skill by relating trade performance to manager type along two dimensions. First, we categorize funds by investment style. We find that growth-oriented managers generate alpha that stems from stock selection skill, while value managers outperform the market index as a consequence of their characteristic exposure. Second, we categorize funds by entity type, by comparing trade performance for institutionalized managers with boutiques, which are typically smaller, recently established and more entrepreneurial. We find stronger evidence of skill amongst boutiques. Finally, our study provides valuable out-of-sample evidence on US findings. Australia is a much smaller and more concentrated market that is likely to have different information asymmetries as compared with the 'bigger pond' of the US market, which may create more opportunities for fund managers to exploit. Consistent with this notion, we find clearer evidence of skill amongst Australian managers relative to US findings. ${ }^{1}$ Further, our monthly holdings data permits more precise measurement of actual trade decisions as compared with the quarterly data available to US researchers. We confirm the advantage of using monthly inferred trades by estimating the extent to which less granular quarterly holdings produce downward-biased estimates of manager skill.

Our analysis investigates trades inferred from a unique dataset of monthly portfolio holdings for 156 long-only active Australian equity funds over a 16-year time period (1994-2009). This dataset 
offers particular advantages over prior research. Not only does the use of monthly portfolio holdings improve the precision of trade identification and hence measurement of abnormal returns, but the dataset covers a longer time period and a wider universe of funds than previously examined in Australian research. This allows us to re-evaluate the sizeable alphas reported in earlier Australian studies. Our analysis focuses on active trading in order to more accurately identify how informative fund managers are in relation to stock selection. In contrast, analysis of holdings or total portfolio returns can obscure skill, since managers will passively hold some stocks due to considerations such as tracking error management, transaction cost minimization, mitigation of capital gains tax and portfolio diversification. Returns associated with stocks traded are evaluated both versus the characteristic-matched benchmarking method of Daniel et al. (1997), and excess returns relative to the market index.

Our results provide strong evidence that stock selection skill exists within our sample of Australian equity managers. We initially examine the returns associated with Buy and Sell trades in aggregate, thus providing a benchmark against which prior studies may be compared. This analysis reveals that Buys are associated with significantly positive abnormal returns (adjusted for characteristics), which are mainly accrued up to 3 months after the trade, followed by a partial reversal. Sells are associated with negative abnormal returns, the magnitude and significance of which increase over 12 months. The cumulative net alpha difference associated with Buys-Sells after 12 months is $1.41 \%$ based on the characteristic-adjusted measure of Daniel et al. (1997) (denoted 'DGTW'), and $1.42 \%$ based on excess returns relative to the market index.

In order to better identify stock selection skill, we then categorize trades to isolate those with a higher probability of being motivated by information, rather than being associated with portfolio rebalancing or liquidity flows. First, we condition on trade size under the hypothesis that larger trades signal a higher probability of being information-motivated. Consistent with this expectation, the outperformance associated with trades is found to be concentrated in the largest trade quartile, where the cumulative net DGTW alpha difference for Buys-Sells increases over time to 2.71\% after 12 months. Meanwhile, performance in the other trade size categories reveals no clear pattern and is rarely significant. Second, we condition on active position as measured by stock weighting relative to the benchmark index to isolate trades which are more important to portfolio construction. Our hypothesis here is that trades designed to either establish or extend an active position are more likely to be motivated by informed trading, as they indicate a meaningful change in the 'bet' being placed on a stock. We find that Buy trades that either first establish, or extend an existing, overweight position are associated with significantly positive abnormal returns. Sells that establish or extend an underweight position generate negative abnormal returns, with those extending an underweight being the most negative and statistically significant. In contrast, returns to trades more likely to have other motivations, such as rebalancing, are mixed and mainly insignificant. In addition, alpha remains positive and mostly significant 9-12 months afterwards for trades more likely to be motivated by information, consistent with skilled trading, rather than price pressure effects.

Our study also provides an investigation of how skill varies across manager type. Our analysis of the trades for funds categorized by self-declared investment style suggests that, on average, fund manager trades are indeed aligned with investment philosophy (and are therefore "true to label'). We find that growth-oriented managers produce significantly positive DGTW alpha from their trades, especially during the first 3 months, thus demonstrating their superior stock selection skill. Value funds generate return patterns associated with their trades consistent with contrarian strategies aimed at capturing longer-term reversals. While their trades generate outperformance versus the market index, this can be accounted for by exposure to characteristics, thus questioning the existence of stock selection skill for the Value manager group. We further compare the trade performance of boutique versus institutionalized managers, thus gauging 
whether there is any relation between skill levels and the ownership or organizational structures of fund management entities. Our analysis finds that the trades of boutique managers outperform those of institutional managers, largely through the success of their Buy trades. These results are consistent with the notion that boutiques can be differentiated in ways that may lead to superior performance, including being owner-manager operations which are incentivized to perform, having less funds under management and hence fewer capacity constraints (Berk and Green, 2004), and their greater propensity to be high-conviction managers, holding a higher proportion of active shares (Cremers and Petajisto, 2009).

Finally, we compare performance based on trades imputed from monthly versus quarterly portfolio holdings. Studies by Fong et al. (2007) and Elton et al. (2011) illustrate the benefit of using inferred trades from more frequent portfolio holdings to identify manager skill. These authors suggest that the major problems associated with using less frequent portfolio data include missing intra-period transactions (either purchase and sale, or sale and re-purchase), and greater imprecision in estimating the timing of trades, which may occur at any time over the measurement interval. Elton et al. (2011) empirically test the effect of the frequency of holdings data, concluding that use of monthly holdings improves predictive power. We confirm these findings for our dataset. Trades inferred from quarterly holdings generate meaningfully lower abnormal return estimates than those based on monthly holdings. The cumulative DGTW alpha difference for Buys-Sells after one year is estimated at $+0.40 \%$ on quarterly inferred trades, versus $+1.41 \%$ based on monthly inferred trades. These results strongly suggest that less frequent data lacks precision in identifying trading skill. Such evidence is consistent with the downward bias in performance estimates at quarterly snapshots with Puckett and Yan (2011).

The study proceeds as follows. Section 2 provides background, including a brief review of related literature. Section 3 details the data and presents descriptive statistics. Section 4 outlines the research design. Section 5 reports the empirical findings related to fund manager skill. Section 6 compares results based on monthly and quarterly holdings data. Section 7 concludes.

\section{Background}

The performance of active managers has been evaluated in the literature using three approaches: (1) realized returns at the aggregate fund level; (2) analysis of returns associated with portfolio holdings of stocks comprising the fund; and (3) an examination of the returns accruing to actual or inferred trades made by the manager. This study applies the third approach by analysing the inferred trades of active Australian equity funds, and is useful in understanding the micro-level portfolio decisions in alpha generation.

Aggregate return-based measures provide an estimate of the overall investment outcome experienced by investors in a fund. However, they may be criticized as noisy proxies for the underlying skill of managers due to failure to take into account aspects that drive a wedge between fund performance and manager skill, such as transaction costs and other constraints (e.g. Kothari and Warner, 2001; Pastor and Stambaugh, 2002a, 2002b). Some researchers have used a portfolio holdings approach to overcome these estimation problems, including Grinblatt and Titman (1989, 1993), Daniel et al. (1997), Wermers (1999, 2000), Chen et al. (2000), and Schultz (2010) in the USA; and Pinnuck (2003) in Australia. Nevertheless, portfolio holdings are still not unencumbered as a measure of underlying skill, as adjustment frictions and constraints may inhibit managers from fully expressing their judgements in their actual portfolio. As actual trades undertaken by managers are often motivated by information, they are potentially more closely aligned with any underlying skill. However, trades may occur for a range of reasons other than informed trading, including portfolio rebalancing, response to fund flows and risk 
management considerations. Our aim is to improve identification of underlying skill by not only focusing on trades, but also by categorizing those trades in accordance with the likelihood that they are information-motivated.

A number of authors have examined the performance of stocks associated with manager trades. ${ }^{2}$ Some studies use actual trade data, although the majority infer net trades from changes in portfolio holdings. While this research generates mixed results; the general finding is that trades tend to be associated with subsequent outperformance in a manner consistent with the existence of manager skill. Chen et al. (2000), Pinnuck (2003), Kacperczyk et al. (2005), Gallagher and Looi (2006) and Alexander et al. (2007) provide evidence of performance asymmetry between fund purchases and sales. Duan et al. (2009) find that Buys outperform Sells only when the trades take place in portfolios exhibiting high idiosyncratic volatility, ${ }^{3}$ with stronger results for 3- and 6-month horizons, suggesting that trading is more successful over the medium term. Baker et al. (2010) assess the stock-picking skill of fund managers by measuring returns associated with future earnings announcements on stocks they have recently traded. Bennett et al. (2003), Yang and Zhang (2009) and Foster et al. (2011) find that institutional trading has positive predictive ability for the next quarter's returns, although the opposite is found by Cai and Zheng (2004). Christoffersen et al. (2007) conduct an analysis of the Canadian mutual fund industry, where the Ontario Securities Commission requires all funds to report individual transactions. They document that active managers significantly outperform index managers through patient trading and informed stock-picking. Puckett and Yan (2010) examine the actual trades of 776 institutional investors from 1999-2004. They find an asymmetric price response between purchases and sales, with results indicating that Buys, while associated with short-term herding, appear information based.

Unfortunately, much of the trade-based analysis suffers from data that is lacking in either quality or sample size. The bulk of US work uses inferred trades from quarterly holdings, which exposes the analysis to missing intra-quarter transactions and imprecision in identifying the timing of the trades. Some authors have explicitly considered how the frequency of holdings data may influence performance measurement. Elton et al. $(1996,2010,2011)$ conclude that using more frequent holdings data permits more precise estimation of the timing of trades, thus leading to greater precision in identifying skilful managers. Kacperczyk et al. (2008) investigate the value of unobserved activity using the 'return gap' between reported fund returns and returns based on disclosed fund holdings, finding that it has predictive power for future performance. In Australia, research efforts have been constrained by the length and breadth of available datasets. Researchers such as Gallagher and Looi (2006) and Foster et al. (2011) have used a proprietary dataset which contains daily trade data for about 34 funds from 1995 to 2001. The data of Pinnuck (2003) covers 35 funds from 1990 to 1997. The current study helps alleviate these shortcomings by using a comprehensive dataset of monthly holdings for 156 funds spanning a period of 16 years. We also provide estimates to indicate the advantages of inferring trades from monthly holdings relative to the less granular quarterly holding data used by most US studies.

\section{Data}

Data on monthly stockholdings for Australian long-only equity fund managers over the 16-year period from January 1994 to December 2009 was sourced from Russell Investments' research database. Russell Investments classifies funds in their database according to five style categories: GARP (Growth-At-a-Reasonable-Price); ${ }^{4}$ Growth; (style) Neutral; Value; and Quant (modeldriven). ${ }^{5}$ The style categories are tailored to the Australian market, with managers self-declaring as to which category they belong under guidance from Russell Investments' researchers. ${ }^{6}$ Russell Investments also identifies funds considered to be 'boutiques'. Identification is based on the 
judgement of Russell Investments' researchers, taking into account aspects such as ownership, organizational structure, fund age and assets under management. Monthly data on returns, closing prices, number of shares outstanding and market capitalization for all available domestic stocks listed on the Australian Securities Exchange are obtained from the AGSM (SPPR) database. ${ }^{7}$ Only actively managed long-only Australian equity funds with general market mandates are incorporated in this study, i.e. indexed, small companies and specialist funds are excluded.

Table 1 presents descriptive statistics for the data. The sample increases from 14 funds with aggregate market value of AUD \$9 billion at end-1994 to 109 funds with aggregate value of AUD $\$ 524.9$ billion at end-2009. ${ }^{8}$ It contains 156 individual funds that were in operation at some time over the period. An average of $90 \%$ of fund holdings by number and $94 \%$ by value are S\&P/ASX 300 Index constituents. This database provides the largest and most complete sample of fund holdings of active Australian equity managers used by any Australian fund study to date.

Our analysis indicates that survivorship and selection bias are not significant within this database. In contrast to the USA, Australia is a relatively small market with a limited number of managers. Consequently, Russell Investments aims to maintain a comprehensive real-time record of all managers operating in the market. There is also no minimum survival requirement for a fund to be included in their database. This makes Russell Investments' Australian database less likely to exhibit survivorship bias and selection bias, although it is possible that the sample may not be fully comprehensive to the extent that some managers do not report data such as portfolio holdings to Russell Investments.

To gauge the magnitude of any selection bias, we adopt the methodology of Ainsworth et al. (2007) by examining the performance differential between new funds and pre-existing funds within the Russell Investments universe. Over the sample period, new funds outperformed preexisting funds by a statistically insignificant average of $0.166 \%$ in net returns per month, equating to an addition of $0.048 \%$ per month to overall sample returns. ${ }^{9}$ This estimate represents an upper limit for potential selection bias. This approach assumes that new funds and pre-existing funds are drawn from a population with the same unconditional mean, but new funds are added to the universe on the condition that they have good observed performance. In practice, there could be genuine reasons to expect new funds to outperform pre-existing funds, such as the boutique effect investigated later in this paper. We consider that selection bias is unlikely to have any meaningful impact given the magnitude of the return difference between new and pre-existing funds; the fact that the difference has other valid explanations; and the manner in which the sample is collected.

\section{Research design}

We conducted an event study, where the event was an inferred trade from portfolio holdings during month $m_{0}$. We examined the abnormal returns associated with stocks that were traded, both on a monthly basis from 6 months prior to the trades $(m-6)$ through to 12 months subsequent to the trades $(m+12)$, and on a cumulative basis for up to 12 months subsequent to the trades $(m+12)$. This section sets out our approach to measuring trades, estimating abnormal returns and aggregating these returns. It also discusses the categorization of trades and analysis of skill by manager type.

\section{I. Trade measure}

Net trades were inferred initially from monthly (and later quarterly) observations of portfolio holdings using the method outlined in Pinnuck (2003). This method infers trades using Equations (1) to (3), which calculate the change in the weight of stock $i$ in fund manager $j$ 's portfolio from the 


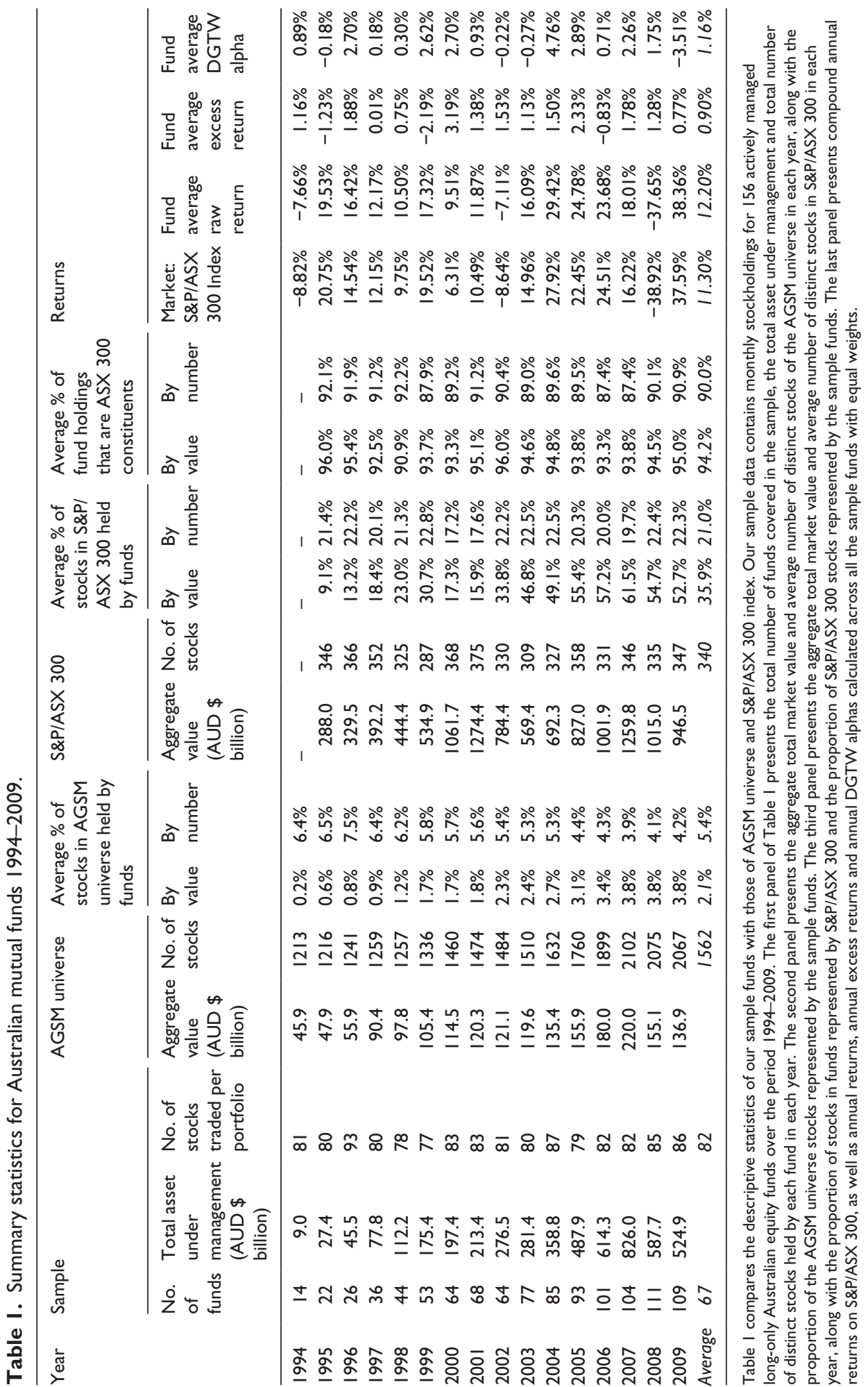


beginning to the end of the period $t$, where opening and closing weightings are both estimated based on end of period $t$ prices.

$$
\text { Trade }_{i j t}=w_{i j t}-w_{i j t-1}^{p t} \text {, }
$$

where $w_{i j t}$ and $w_{i j t-1}^{p t}$ are defined as follows:

$$
\begin{gathered}
w_{i j t}=\frac{P_{i t} H_{i j t}}{\sum_{i=1}^{N} P_{i t} H_{i j t}}, \\
w_{i j t}^{p t}=\frac{P_{i t} H_{i j t-1}}{\sum_{i=1}^{N} P_{i t} H_{i j t-1}},
\end{gathered}
$$

where $P_{i t}$ is the price of stock $i$ at time $t, H_{i j t}$ is the number of shares held by fund manager $j$ in stock $i$ at time $t$, and $N$ is the number of different stocks held by each fund manager.

Both the weight at the beginning of time $t, w_{i j t-1}^{p t}$, and the weight at the end of time $\mathrm{t}, W_{i j t}$, are evaluated a price, $P_{i t}$, which allows us to mitigate any spurious effect of price movements within the period on the change in portfolio weights.

It is worthwhile to elaborate on the inferred trade measure and its suitability. This is important to address because not all changes in portfolio weights are the result of actual trades. They reflect the net effect of various components that determine the estimated portfolio weights. In essence, the trade measure we employ is an estimate of the net change in active position across an entire month in each stock. Arguably, the change in active position is the most appropriate measure for the purpose of evaluating manager skill. Given that active fund managers aim to beat the market by making 'bets' relative to capitalization-weighted indices, changes in weights provide a direct measure of the net adjustments to the portfolio in pursuit of this goal. It is possible that change in portfolio weights may not align with actual trades for two reasons. ${ }^{10}$ One is where trades associated with cash inflows or outflows are not applied proportionately across the portfolio, in which case our measure will infer trades that are at odds with actual physical trades. ${ }^{11}$ Nevertheless, imputed trades may be interpreted as the marginal trades that would be required to establish the observed weights, relative to a baseline where cash flows are initially applied to all stocks proportionately. The other possibility is that trades may be spuriously inferred as a result of using incomplete portfolio holding data. While this possibility exists, our understanding is that the stock holding data in the Russell Investments database is substantially complete, with the main issue being that we exclude any derivative and cash positions from this study. In any event, incomplete holdings data would only add noise to the trade estimates, which should bias the results against finding evidence of skill if it exists.

\subsection{Performance benchmarks}

Abnormal returns are measured against two benchmarks in this study: returns in excess of the market index ('excess returns'), and DGTW characteristic-adjusted returns ('DGTW alphas'). Excess returns are estimated relative to the S\&P/ASX 300 Index. $^{12}$ The DGTW 
approach ${ }^{13}$ evaluates returns against a matched benchmark portfolio with similar exposure to size, book-to-market and momentum characteristics. DGTW alphas are calculated by subtracting returns of the assigned benchmark portfolios from the individual returns for the stock being evaluated. The DGTW approach has been widely used in the fund management literature. Daniel et al. (1997) use their measure to decompose performance into stock-picking, style-timing and style-based returns. The approach has also been applied outside the USA. For example, Wylie (2005) constructs characteristic-based benchmarks for the UK market to study the tendency of herding, while Iihara et al. (2004) use characteristic-based portfolios for stocks on the Tokyo Stock Exchange to study momentum trading. The DGTW approach has been used to construct benchmarks in the Australian market by Pinnuck (2003), Gallagher and Looi (2006) and Fong et al. (2007).

As noted by Gallagher and Looi (2006), the DGTW performance measures require modification when applied in Australia due to the relatively small number of stocks and high degree of market concentration. Brands et al. (2005) document that the market capitalization weights of the largest 20 stocks listed on the Australian Securities Exchange (ASX) exceed 62 percent of the market capitalization of the stocks included in the S\&P/ASX 300 Index. Accordingly we use a variation of the DGTW method to construct size, book-to-market and momentum characteristic-based benchmark portfolios as follows. As at each December beginning in 1993, all stocks in the AGSM database satisfying the data requirements ${ }^{14}$ are placed into 60 value-weighted characteristic-based benchmark portfolios under a $5 \times 4 \times 3$ sort. The process involves initially sorting stocks into five portfolios based on market capitalization just prior to formation date. Firms in the size portfolios are further sorted into four portfolios based on their book-to-market ratios, calculated from the book value at the end of the firm's fiscal year preceding the formation date divided by the market capitalization at the end of the preceding June. The final characteristic-based benchmark portfolios are formed by sorting the 20 size and book-to-market portfolios into three further portfolios based on momentum, as measured by their preceding 12-month return calculated through to the end of November. This is our preferred measure, and results are reported for this measure only. To examine the robustness of our results, we also constructed 27 alternative characteristic-based portfolios based on a $3 \times 3 \times 3$ sort. Results from both DGTW measures were consistent. ${ }^{15}$ Our approach follows Pinnuck (2003) and Fong et al. (2007), who conduct a similar analysis on Australian markets by respectively splitting the stock universe into $60(5 \times 4 \times 3)$ and $27(3 \times 3 \times 3)$ buckets. This approach contrasts with the $125(5 \times 5 \times 5)$ portfolios formed by Daniel et al. (1997) from the CRSP database.

\subsection{Abnormal returns associated with individual trades}

Excess returns and DGTW alphas are initially calculated on both a monthly and a cumulative abnormal return basis for each observed trade. Monthly excess returns (ER) and cumulative excess returns (CER) are estimated using Equations (4) and (5), respectively. Monthly DGTW alphas (DGTW) and cumulative DGTW alphas (CDGTW) are estimated using Equations (6) and (7).

$$
\begin{gathered}
E R_{i, t}=R_{i, t}-R_{b, t} \\
C E R_{i, t=m+x}=\prod_{t=m+1}^{m+x}\left(R_{i, t}+1\right)-\prod_{t=m+1}^{m+x}\left(R_{b, t}+1\right),
\end{gathered}
$$


where $R_{i, t}$ is the month $t$ return of stock $i$, and $R_{b, t}$ is the month $t$ return of the S\&P/ASX 300 Index.

$$
\begin{gathered}
D G T W_{i, t}=R_{i, t}-R_{t}^{b i, t-1} \\
C D G T W_{i, t=m+x}=\prod_{t=m+1}^{m+x}\left(R_{i, t}+1\right)-\prod_{t=m+1}^{m+x}\left(R_{t}^{b i, t-1}+1\right),
\end{gathered}
$$

where $R_{i, t}$ is the month $t$ return of stock $i$, and $R_{t}^{b i, t-1}$ is the month $t$ return of the characteristic-based benchmark portfolio matched to stock $i$ during month $t-1$.

\subsection{Aggregation of abnormal returns}

To estimate aggregate measures of abnormal returns associated with trades, we adopted a twostage approach. First we estimated the weighted abnormal return across all observed trades for each fund, where weights were based on relative Trade size for that fund. We then calculated a simple average of abnormal returns across all funds. This approach was adopted due to large differences in the level of portfolio concentration and hence trade sizes across funds. For instance, a trade equating to (say) $2 \%$ of the portfolio could be a small- or average-sized trade for a fund with concentrated positions, but a large trade for a more diversified fund. Our approach is designed to attribute more weight to trades that are relatively large from the perspective of each manager, given their observed trading history. Each fund was then given equal weighting in aggregate abnormal return estimates.

Equations (8) and (9) describe the calculation with respect to monthly excess returns. Calculations for monthly DGTW alphas, CER and cumulative DGTW alphas all take the same form. Equation (8) estimates the excess return for period $m+x$ across all $N$ trades for a particular fund $j$. The trades are weighted by $\operatorname{Trade}_{i j t}$ (see Equation (1)) for stock $i$ as at $m_{0}$. Effectively this weights trades by the change in active weighting. Equation (9) aggregates returns for period $m+x$ across funds.

$$
\begin{gathered}
E R_{j, t=m+x}=\sum_{i=1}^{N(j)}\left[E R_{i, m+x} \frac{\text { Trade }_{i j, m 0}}{\sum_{i=1}^{N(j)} \operatorname{Trade}_{i, j, m 0}}\right] \\
E R_{t=m+x}=\sum_{j=1}^{N(f)}\left[\frac{E R_{j, t=m+x}}{N(f)}\right],
\end{gathered}
$$

where $E R_{i, m+x}$ is the excess return for stock $i$ in month $t+x$, Trade ${ }_{i, j, m 0}$ is the trade value in stock $i$ for fund $j$ as at $t=m_{0}, N(j)$ is the number of observed trades for fund $j$, and $\mathrm{N}(f)$ is the number of funds in the sample. 


\subsection{Trade categorization}

Identification of trades which are more likely to be motivated by information, rather than portfolio rebalancing or liquidity, involves categorization by trade size and active position. Categorization by trade size is based on sorting all available Buy and Sell trades respectively for each fund into four quartiles. This means that the top quartile captures the largest $25 \%$ of portfolio weight changes for each manager. Abnormal returns for each trade category are then aggregated for each fund and then across funds in the manner described in section 4.4. The motivation for initially sorting across all aggregate trades per fund is that funds may differ in their typical trade size due to aspects such as portfolio concentration and trading strategies - what may be a large trade for one fund may only be a modest trade for another. Categorizing trades by reference to the distribution of trades for the fund in question increases the likelihood that the upper quartiles will contain the larger, and hence more meaningful, trades for each fund.

Categorization by change in active position references the difference between the weighting of the stock in the portfolio relative to its weighting in the S\&P/ASX 300 Index in both the pre-trade $(m-1)$ and post-trade $(m 0)$ period. Stocks were then categorized as underweight relative to the Index ('under'); overweight relative to Index ('over'); or nil holding ('zero'). A $0.25 \%$ band around weighting relative to the Index is imposed to identify transitions between 'over' and 'under' weight. This ensured that only meaningful changes in active position were identified, and helped insulate the analysis against the influence of trades that may have been spuriously identified due to data issues. Trades were categorized into sub-groups by comparing portfolio weights in the pre and post periods. This generated five categories for Buys and Sells. The Buy categories are: (a) pre under, post under, (b) pre under, post over, (c) pre zero, post under, (d) pre zero, post over ('initiation Buys'), and (e) pre over, post over. Sell categories are a mirror image, with any sales that establish a zero weight called 'liquidation Sells'. Trades within each category were aggregated in the manner described in section 4.4 .

Categorization by active position assists in isolating trades that are more likely to involve informed trading in the following manner. If a trade establishes an active position that was not previously in existence, then this might be taken as a strong signal of a change in view about the stock in question. The trade categories that are aligned with a clear change in position include Buys that move the portfolio from either zero or under to overweight, or Sells that move the portfolio from over to under or zero weight. Similarly, extending an existing active position may be viewed as confirmation of a prior view. This would be most clearly indicated by Buy trades that add to an existing overweight, and Sell trades in the context of an existing underweight. ${ }^{16}$ By contrast, Sells where the portfolio remains underweight in the pre and post period, or Buys where the portfolio remains overweight pre and post, are more difficult to interpret and more likely to involve portfolio rebalancing. In this case, an existing active position is retained, but is being adjusted towards a lower level. In any event, the extent to which such trades indicate informed trading versus other motivations is unclear.

\subsection{Examination of fund type}

An understanding of how returns vary with fund type can aid the construction of multi-manager portfolios. Investment style is an important consideration in this respect. Barberis and Shleifer (2003) highlight a growing interest in style investing. They argue that style categorization allows efficient processing of information and ease of manager evaluation. An understanding of style provides valuable insights for fund-of-funds (e.g. pension funds) considering delegating assets across funds with different styles, and can assist with the control of overall risk. Another aspect of 
interest to multi-manager investors is whether ownership structure influences the potential for alpha generation.

Our examination of the link between alpha generation and a fund manager's self-declared investment style was in part motivated by the work of Foster et al. (2011). Our focus was on separating the return contribution of skill from style, and gauging the interaction between style and the horizon over which any outperformance is realized. We aimed to investigate how style specialization relates to manager skill, and whether styles are simply outcome-oriented investment strategies to attract a particular group of investors. Value managers, for example, are expected to trade more heavily and successfully on high book-to-market stocks and judgements about long-term fundamental value, while growth-oriented managers tend to focus on aspects such as the rate of change in performance (Chen et al., 2000; Gallagher and Looi, 2006). Chan et al. (2002) explicitly consider the potential importance of fund style given non-performance distortions (e.g. agency considerations). They suggest that heightened attention to fund style provides a clearer picture of manager stock selection skill, since performance may appear to be quite different given the nature of product differentiation. We expand on the concepts raised by Chan et al. (2002) by examining trading performance across funds categorized by self-declared investment style.

A test of the hypothesis that differences in skill exist between boutiques and institutional funds is motivated by a number of considerations. Reasons exist to expect performance to differ with ownership structure. According to Russell Investments, ${ }^{17}$ boutiques are characterized as small or emerging fund management entities that have a significant proportion of their equity owned by the individual fund managers within the organization. Typically boutiques have been recently established by experienced ex-employees from institutional funds. As owner-managers, they are highly incentivized to perform by their equity in the business and the option-like payoffs that can arise from building a performance record and growing funds under management. Further, boutiques tend to have relatively low funds under management, meaning that they may face fewer capacity constraints, as discussed by Berk and Green (2004). Finally, boutiques are more likely to be high-conviction managers with more active portfolios, which Cremers and Petajisto (2009) demonstrate to be associated with outperformance. Hence boutiques display a number of attributes that might be expected to align with greater levels of skill. A further interesting question is whether boutiques might be more effective at identifying Buy candidates than underweight positions, given their relatively concentrated portfolios.

Our approach to investigating the relationship between skill and fund type involves applying the methods described in sections 4.1 to 4.4 to sub-samples of funds reflecting the different manager types identified in the Russell Investments database. ${ }^{18}$ The style analysis is based around aggregating results for funds within the five self-declared investment style categories of GARP, Growth, Neutral, Value and Quant. The ownership structure types are based around the two categories of boutique and institutional funds. Funds of unknown type have been excluded from the analysis. In the case of style, specific additional attention has been paid to differences in trade performance based on DGTW alpha and excess returns. This provides an indication of the extent to which returns are accruing to exposure to the characteristics or 'style' versus security selection skill, noting that DGTW alphas provide a measure of security selection skill after deducting return on benchmark portfolios matched along the dimensions of size, book-to-market and price momentum. For instance, a positive difference between excess returns and DGTW alpha would indicate that excess returns contain a positive stylebased component (and vice versa). 


\section{Empirical results}

This section commences by reporting the aggregate results across all trades and funds. Results for trade categories are then reported. Initially we categorize trades by size, followed by portfolio weightings pre and post the trade. We then compare trade performance across fund type, including investment styles and boutiques versus institutional managers.

\section{I. Aggregate results}

Aggregate results across all trades are reported in Table 2. Panel A reports average monthly abnormal return estimates for 6 months prior to the trades and 12 months subsequent to the trades, while Panel B reports cumulative abnormal returns for 12 months subsequent to the trades.

In general, Buys tend to be followed by positive abnormal returns and Sells are followed by negative abnormal returns. Given that the monthly results reported in Panel A are uneven across months and return measures, we will focus on cumulative returns, which better reveal the underlying performance trends. Cumulative DGTW alphas (CDGTW) for Buys increase in magnitude to a peak of $+0.68 \%$ in $m+3$ before fading, remaining positive and statistically significant until $m+7$. CDGTW for Sells are initially negative and insignificant, but continue to increase in magnitude throughout the post-trade period. CDGTW for Sells become significantly negative by $m+10$, and reach the reported low in $m+12$ at $-1.28 \%$. The CDGTW Buy-Sell difference is positive and builds in magnitude and significance throughout the post-trade period, with a reported maximum of $+1.41 \%$ in $m+12$. The CDGTW Buy-Sell difference provides solid evidence that Australian equity managers possess superior stock-picking skill. However, the nature of this skill appears nuanced. Outperformance associated with Buys seems to be of shorter duration, peaking after 3 months; while outperformance associated with Sells builds over time. The notion that managers may have asymmetric information content with respect to Buys and Sells is consistent with other findings. Pinnuck (2003) and Gallagher and Looi (2006) both find evidence of significant short-term outperformance for Buys but not for Sells for Australian equity funds, with Pinnuck finding that Buy returns fade after 2-3 months. However, neither paper examines performance beyond 6 months, which is where we discover Sells significantly underperform the market, hence adding to manager alphas. Our Sell results are consistent with Chen et al. (2000), who find that the Sell trades of US equity mutual funds generate significant alphas only beyond 6 months. On the other hand, Chen et al. (2000) find that Buy returns not only occur immediately, but also continue to build over four quarters.

A different pattern emerges for CER. The CER for Buys are initially positive and insignificant, but continue to increase in magnitude throughout the post-trade period, becoming significant in $m+3$ and reaching a peak of $+1.46 \%$ in $m+12$. The CER for Sells are mostly positive but insignificant throughout. The CER Buy-Sell difference is positive and builds in magnitude throughout the post-trade period, becoming significant in $m+7$ and reaching a reported maximum of $+1.42 \%$ in $m+12$. Bearing in mind that DGTW alphas adjust for the size, book-to-market value and price momentum characteristics of stocks, any observed performance difference between DGTW alpha and excess return is related to characteristic-based premiums rather than the stock selection skill of managers. The difference between the CDGTW and CER results suggests that the Buy trades of Australian equity managers generate short-term (1-3 months) returns from stock selection and medium-term (up to 12 months) returns from characteristic timing; while Sell trades generate medium-term returns from both stock selection and characteristic timing.

Figure 1 plots indices of cumulative abnormal returns for Buys and Sells from $m-6$ through to $m+12$. The chart reveals that both Buy and Sell trades, on average, occur in stocks that have previously outperformed. Nevertheless, there are obvious differences in the post-trade return patterns. 


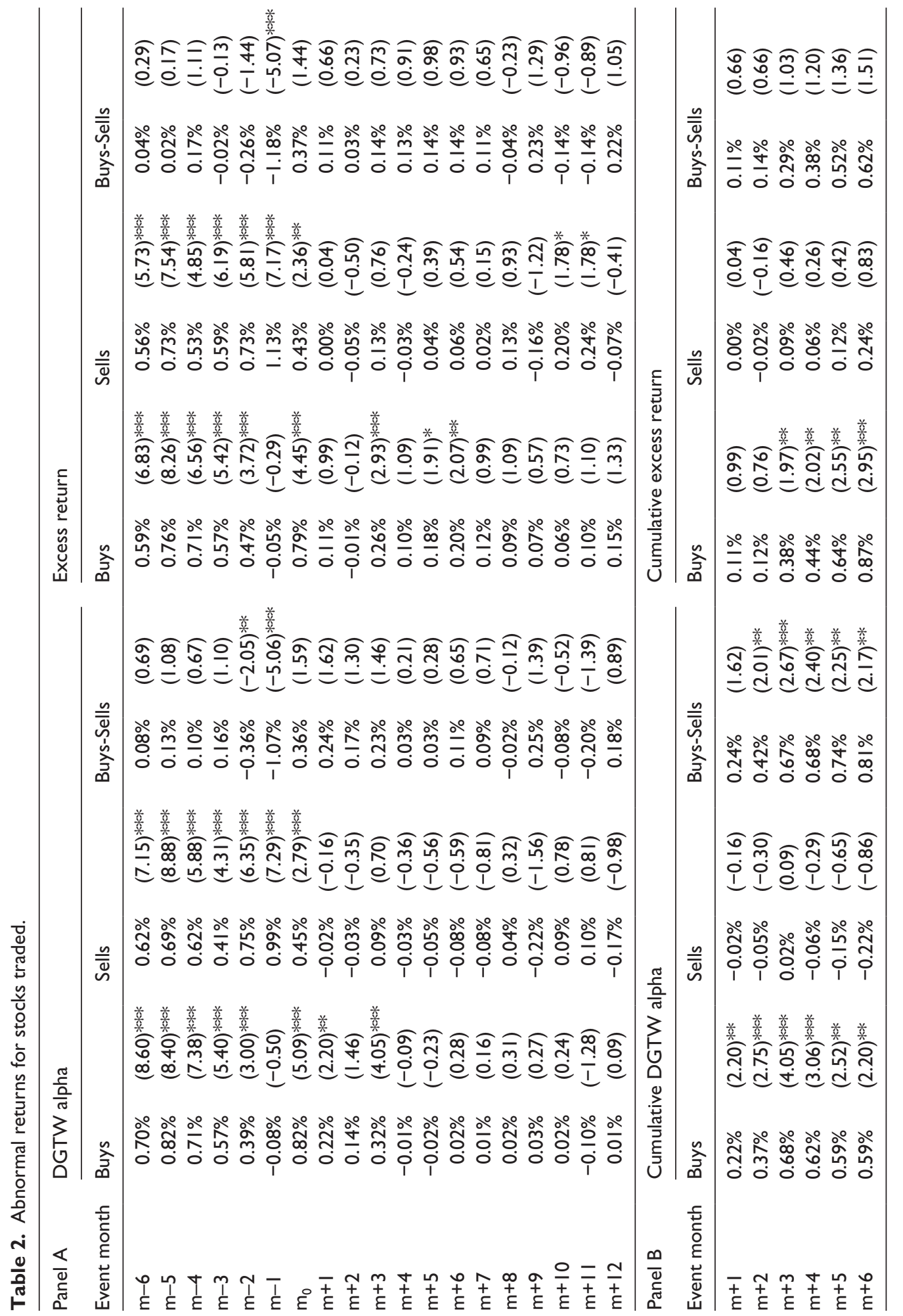




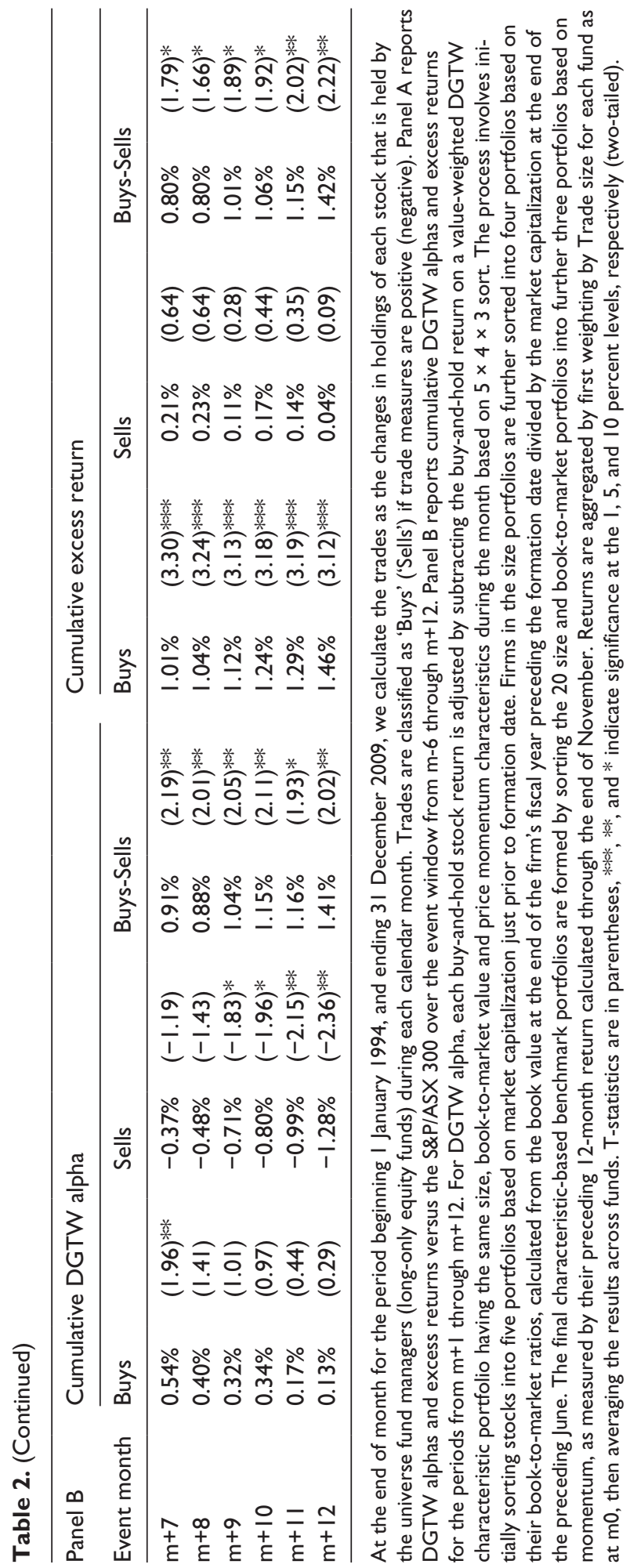




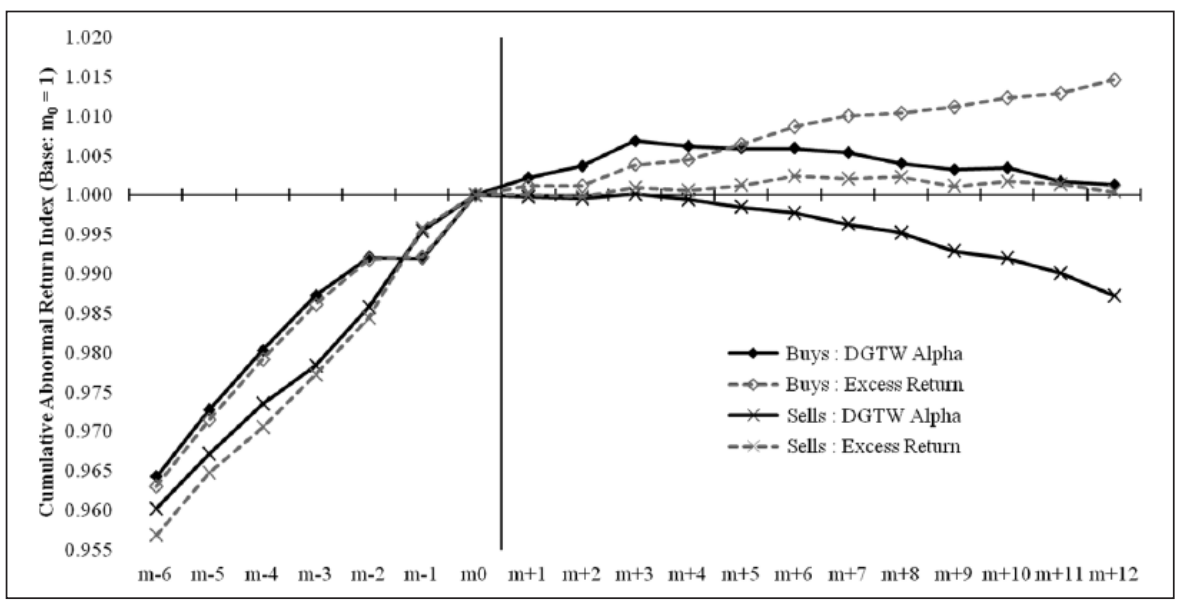

Figure I. Cumulative abnormal return indices.

This hints that Buys and Sells may be motivated by additional information other than just prior performance.

\subsection{Differential performance across trade size}

In this section, we investigate sub-groups of trades of different size. Empirical support for theoretical notions of the information conveyed in trades is provided by Hasbrouck $(1988,1991)$, Algert (1990), Madhavan and Smidt (1991) and Easley et al. (1997). Conventional models of informed trading demonstrate a positive relation between trade size and the probability of informed trading. ${ }^{19}$ Given private information about a security, an informed trader should tend to take a relatively large position. Such justification is even stronger for long-only buyer-initiated block trades, which are more likely to be originated by traders with private information than long-only sellerinitiated trades. ${ }^{20}$ By contrast, Barclay et al. (1993) develop the stealth trading hypothesis, arguing that informed investors are most likely to use medium-sized orders to camouflage their trading motives and minimize price impact.

To investigate the relation between trade size and subsequent returns, Buys and Sells are ranked into quartiles according to the Trade measure, i.e. the relative magnitude of change in active position associated with trades for that fund. Results for each fund in each Trade size group are then averaged across funds. Table 3 presents cumulative abnormal returns for the four Trade size groups. It reveals that the aggregate outperformance reported in Table 2 is essentially sourced from large trades. Large Buys are associated with significantly positive CDGTW that mainly accrues during the first 3 months after the trades, and is sustained at a significant level of around $+1.0 \%$ until $m+7$ before fading. Large Sells are associated with significantly negative CDGTW from period $m+1$, progressively increasing in magnitude to $-2.21 \%$ in $m+12$. The CDGTW Buy-Sell difference for Large trades is significant from $m+1$, and builds to a maximum of $+2.71 \%$ in $m+12$. Meanwhile, CDGTW for all other trade size groups are much smaller, never significant, and mixed overall. Figures 2 and 3 plot the trends.

The results confirm that the patterns seen for CER at the aggregate level are sourced from Large trades. Consistent with Table 2, CER for Large Buys are initially positive and insignificant, but continue to increase in magnitude throughout the post-trade period, becoming significant in $m+3$ 


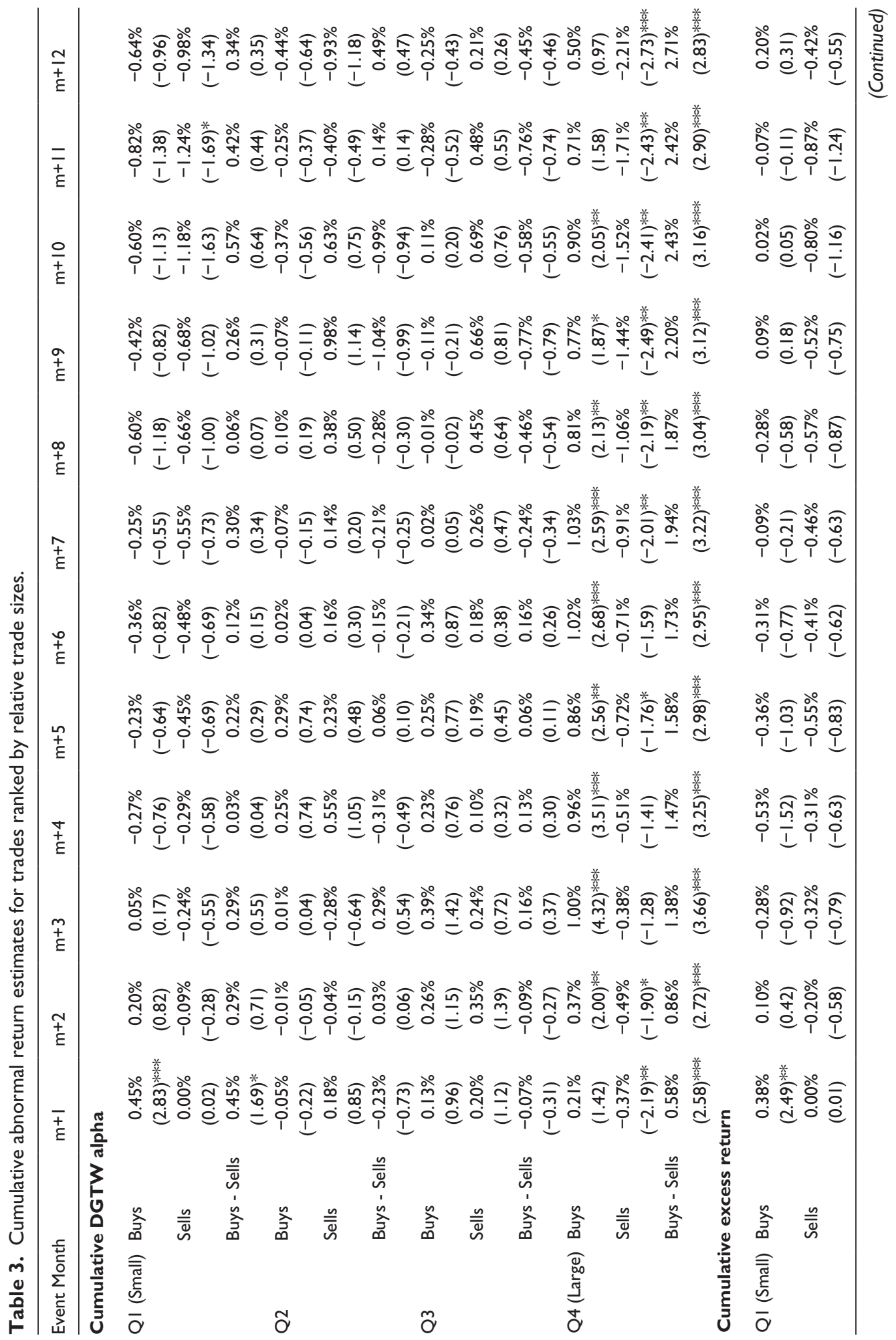




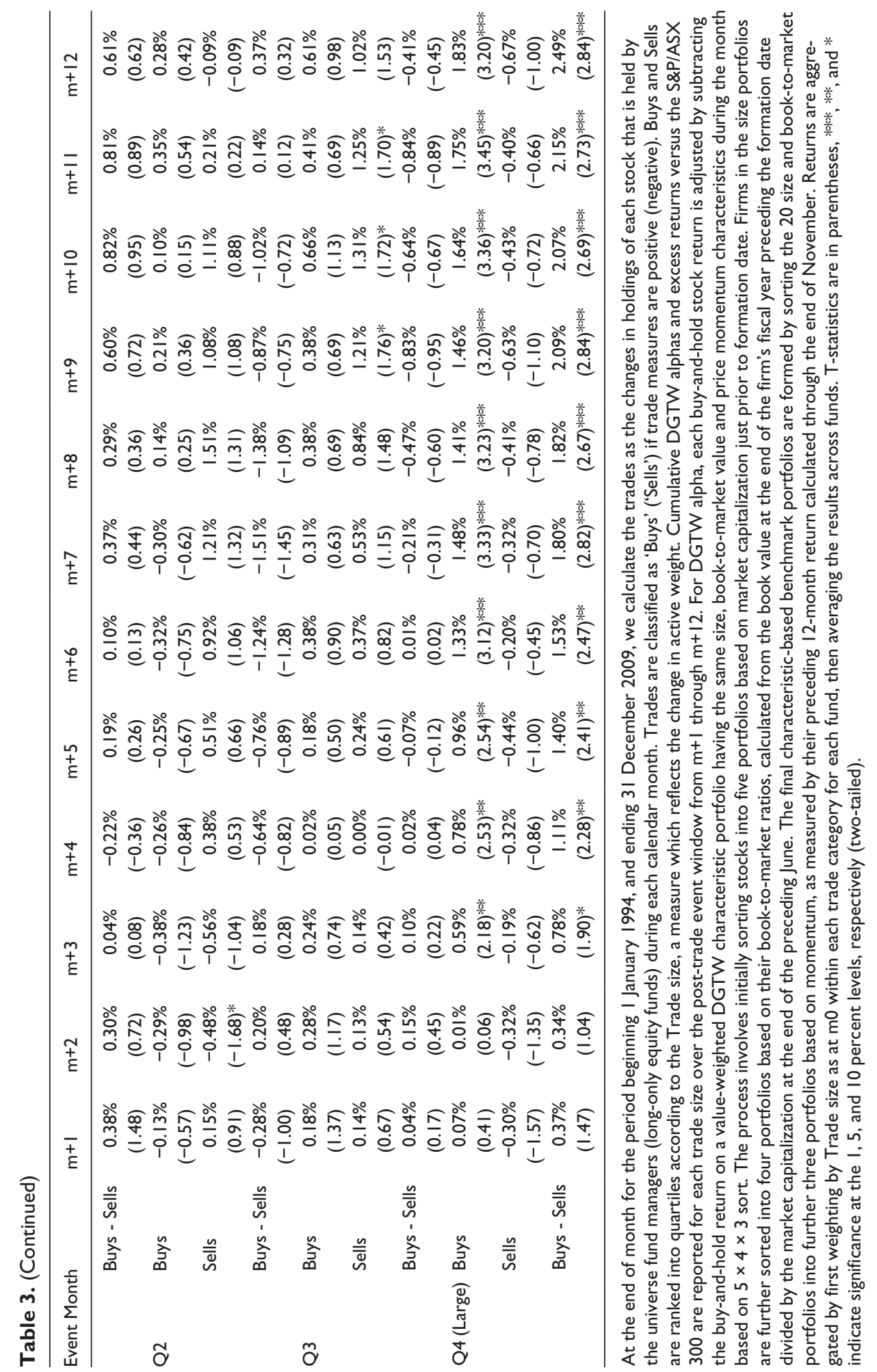




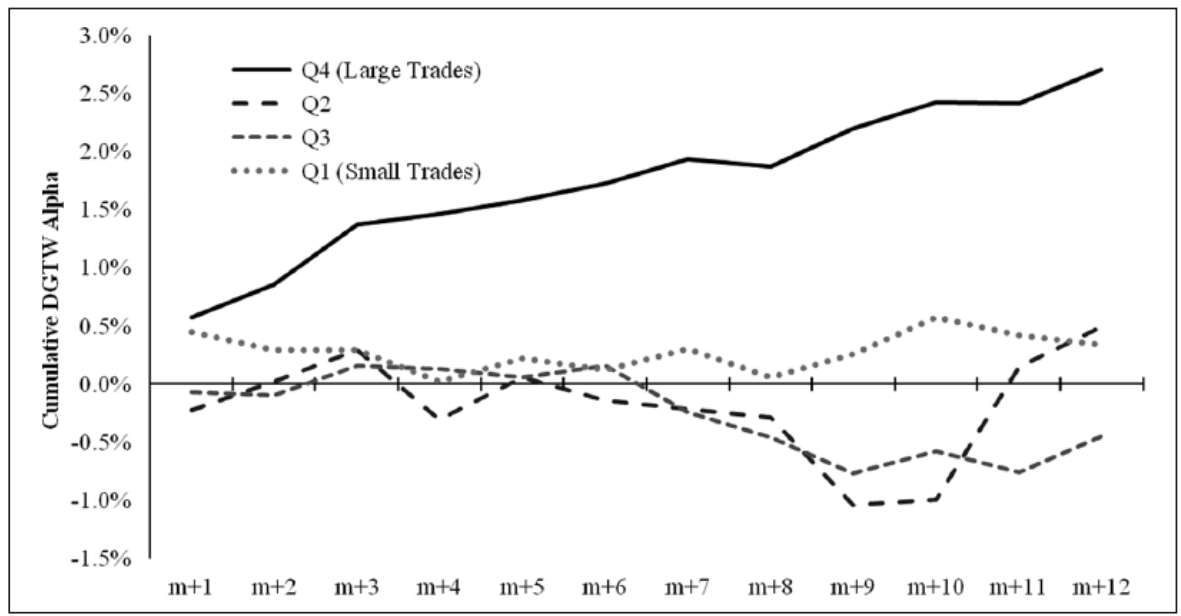

Figure 2. Cumulative buy-sell DGTW alpha classified by trade size.

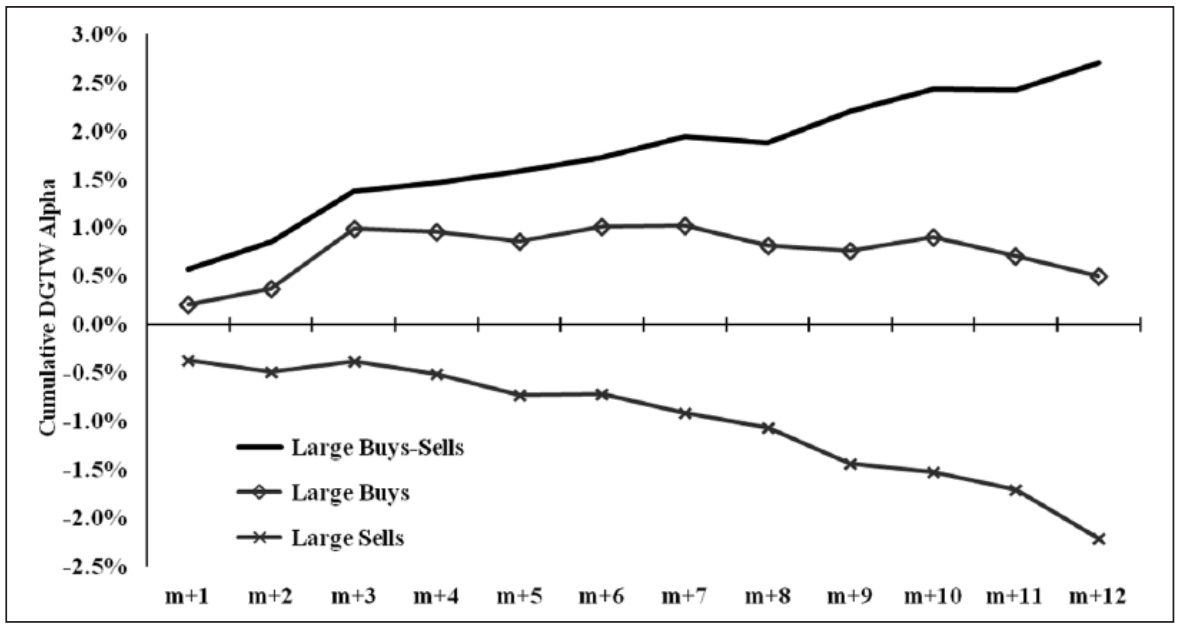

Figure 3. Cumulative DGTW alpha for large trades.

and reaching a peak of $+1.83 \%$ in $m+12$. In contrast to Table 2, CER for Large Sells are negative although still insignificant throughout. The CER Buy-Sell difference for Large trades is positive and progressively builds in magnitude throughout the post-trade period, becoming significant in $m+3$ and reaching a maximum of $+2.49 \%$ in $m+12$. CER for all other trade sizes are much smaller in magnitude and mostly insignificant.

These results reinforce the view that managers possess information which is of value over the short to intermediate term. More specifically, we observe short to intermediate-term buying skill, and intermediate-term selling skill. The results align with the conventional model of informed trading that Large trades are more likely to be information-motivated. By focusing on such trades, the evidence of skill becomes more clearly apparent. In addition, the possibility arises that some small trades may be spurious due to data issues, such as incomplete portfolio holdings. To the extent this is the case, it could contribute to the absence of a relationship between smaller trades and 
subsequent performance. This possibility reinforces the case for conditioning on trade size when aiming to detect the existence of skill, to increase the precision of the signal.

\subsection{Differential performance across portfolio weightings versus benchmark}

Next we conditioned our analysis on change in portfolio weight relative to the S\&P/ASX 300 Index. Trades were categorized according to whether the stock was held 'over', 'under' or 'zero' weight during the 'pre' and 'post' trade periods, in the manner described in section 4.5. Recapping, this gave rise to five sub-groups each for Buys and Sells. Buys are categorized into shifts in weight from: (a) under to under (reducing an existing underweight); (b) under to over; (c) zero to under; (d) zero to over (initiation Buys); and (e) over to over (extending an existing overweight). Sell categories are the mirror image. Our hypothesis is that the trades most likely to be motivated by information are Buys that establish or extend an overweight position; and Sells that either liquidate or establish/extend an underweight position. Conversely, Buys reducing an existing underweight and Sells reducing an existing overweight are more likely to indicate either a tempering in position (rather than an outright change) or portfolio rebalancing. Such trades are less likely to indicate the existence of new information.

Table 4 presents cumulative abnormal return estimates for the 10 categories during the pre and post periods. CDGTW and CER results tell a similar story and confirm our prior hypothesis: trades that are more likely to be motivated by information generate the better outcomes. For Buys, initiation trades that move from a zero weighting to overweight (pre zero, post over) and Buys increasing an existing overweight (pre over, post over) generated abnormal returns of the highest magnitude and significance. This provides evidence of manager skill with respect to Buys, as these are two of the three groups most likely to involve informed trading. However, the third such group (pre under, post over) generated returns that are mixed and insignificant. Buy trade groups that are least likely to be informed (pre zero, post under; pre under, post under) generated mixed and insignificant returns, as expected.

For Sells, the sale of a stock previously held underweight (pre under, post under) was followed by a series of very significant negative returns (CDGTW of $-2.35 \%$ over 12 months, $t$-statistic -4.87). It seems probable that informed trading is the main explanation. Full liquidation Sells (pre over, post zero; pre under, post zero), together with Sells that establish an underweight (pre over, post under), generated negative returns, as expected. However, with a few exceptions, ${ }^{21}$ the returns are insignificant. On the other hand, Sells that reduced an existing overweight (pre over, post over) were followed by significantly positive returns. Given that such trades are the most likely to be motivated by rebalancing, rather than information, ${ }^{22}$ this result is unsurprising.

Figure 4 plots indices of CDGTW from $m$ - 6 through $m+12$ for the four sub-groups where significant abnormal returns occurred in the post-trade period. This plot provides a deeper insight into these stand-out trade types. The most successful Buys occurred in initiation trades where managers moved overweight in stocks that had previously been outperforming (pre zero, post over). These stocks not only generated significant abnormal returns, but, in contrast to the aggregate results for Buys, the abnormal returns built and were sustained over the analysis period, rather than fading. Bearing in mind that the DGTW method adjusts for momentum, it seems that managers have skill in identifying positive momentum stocks which can generate additional abnormal returns that is sustained over an intermediate horizon. Buys that extended an existing overweight (pre over, post over) had a similar pattern in the post-trade period. However, their performance dipped notably in the 2 months prior to the trade, consistent with adding to positions during a correction. Sells that reduced an overweight (pre over, post over) showed very substantial outperformance in the pretrade period, and this outperformance continued post trade. Hence these trades are perhaps best 


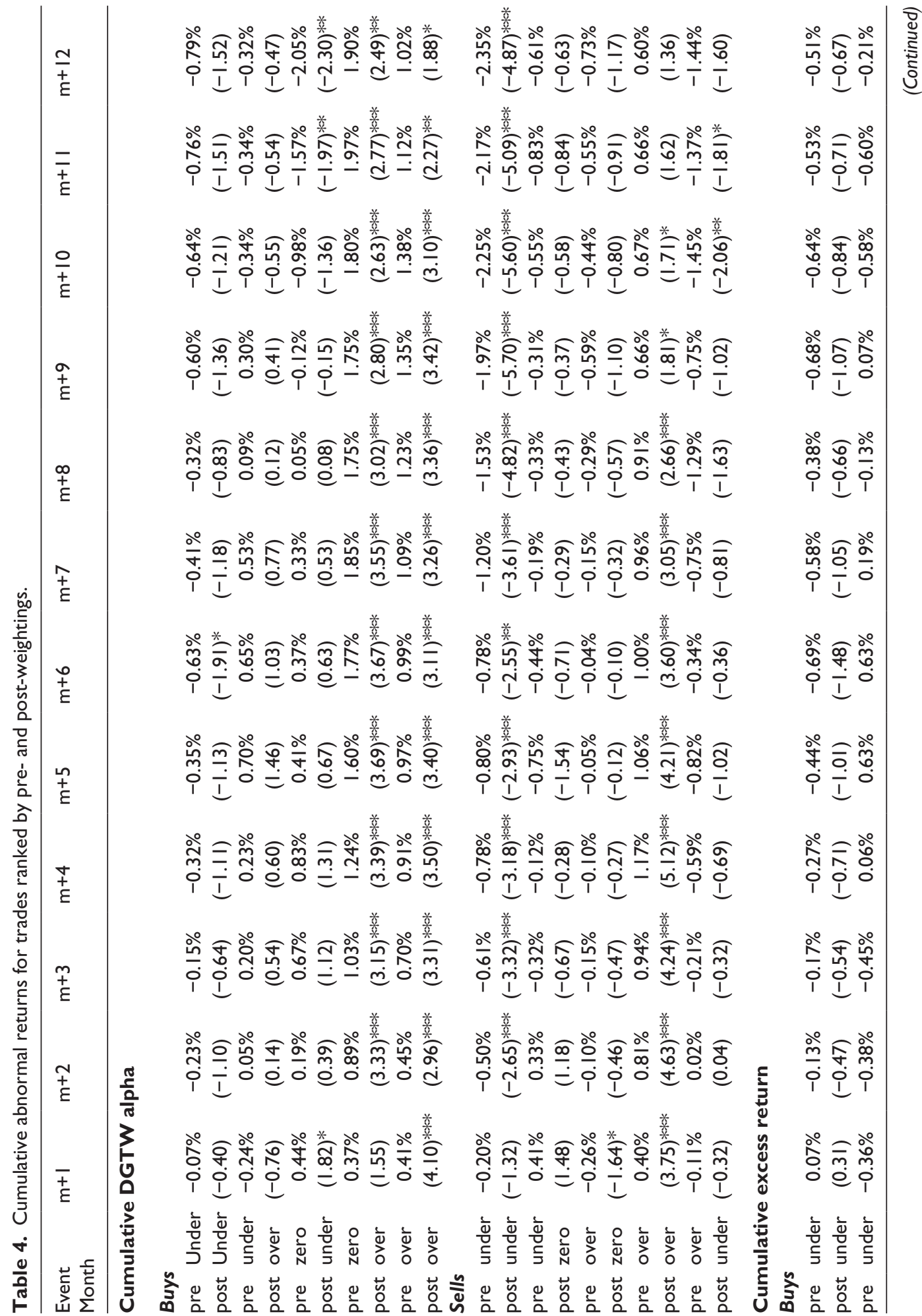




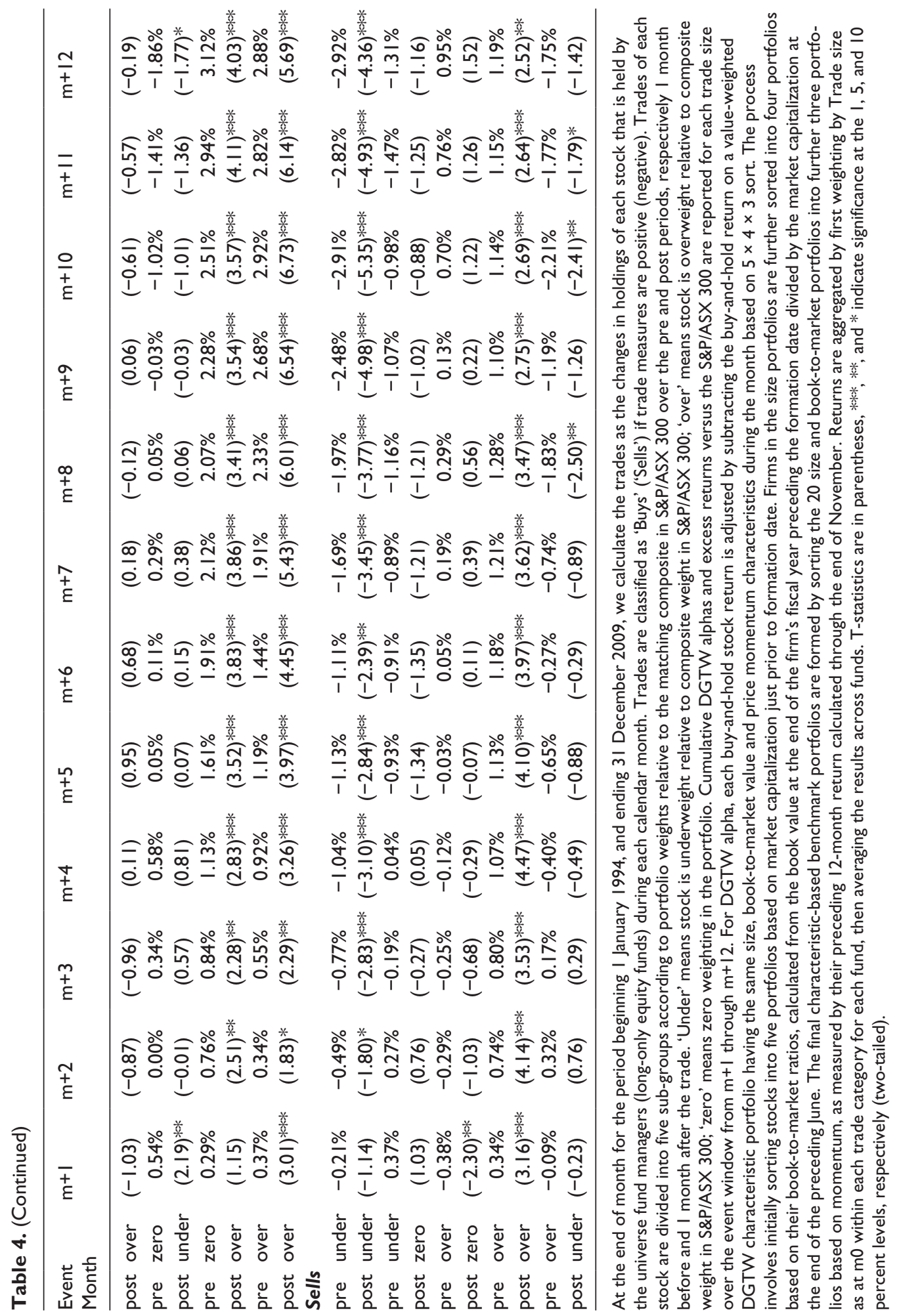




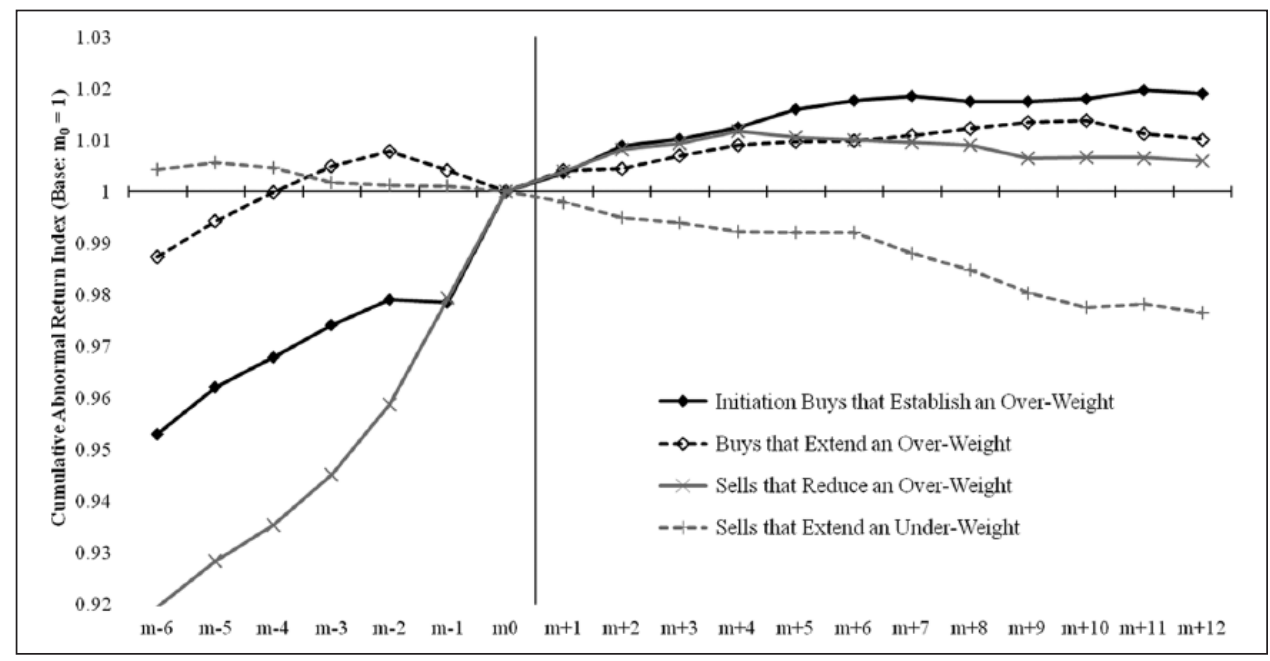

Figure 4. CDGTW alpha for selected pre and post weightings.

described as 'selling into strength', and seem more consistent with prudent portfolio rebalancing, rather than lack of skill. To the contrary, the fund remained overweight and hence benefited from the continued outperformance. In contrast, Sells that extended an existing underweight (pre under, post under) demonstrated very modest underperformance pre-trade, with this underperformance gathering pace in the post-trade period.

Our analysis indicates the benefit of conditioning on relative portfolio weighting when using trades to evaluate manager skill. The shift in portfolio weighting acts as an indicator of trade motivation, and thus helps distinguish trades that are more likely to involve informed trading, rather than rebalancing. Consistent with this notion and the existence of skill, we find that trades establishing or extending a particular position tend to contribute most to outperformance. Further, the abnormal returns to such trades are sustained over the intermediate term, a finding that seems inconsistent with price pressure effects, where reversal would be expected. Meanwhile returns on other trade groupings are either insignificant or generate confounding results. In particular, Sells aimed at reducing (but not reversing) an existing overweighting do not necessarily reflect any negative view on the stock in question, given there is a higher probability of rebalancing and the manager remains overweight. This sub-group of Sell trades has a confounding effect on the aggregate Sell results, obscuring evidence of skill. In summary, when trades are categorized according to pre and post weightings, a more nuanced picture emerges that strengthens the finding that Australian equity managers possess trading skill.

\subsection{Differential performance based on investment style}

This section addresses the question of whether managers can be differentiated in their trading decisions by investment style. Table 5 reports cumulative abnormal returns for each investment style group. Growth-oriented managers (GARP and Growth) offer the clearest evidence of trading skill. CDGTW Buy-Sell differences peak at $+4.19 \%$ in $m+12$ for GARP, and $+2.78 \%$ in $m+10$ for Growth. CDGTW for Buys reach their peaks in $m+10$ for both GARP $(+2.78 \%)$ and Growth $(+2.23 \%)$, with the highest rate of increase occurring up to $m+3$. CDGTW for Sells are insignificant for GARP, reaching $-1.85 \%$ in $m+12$. There is no evidence of significant Sell skill for Growth. In contrast, 


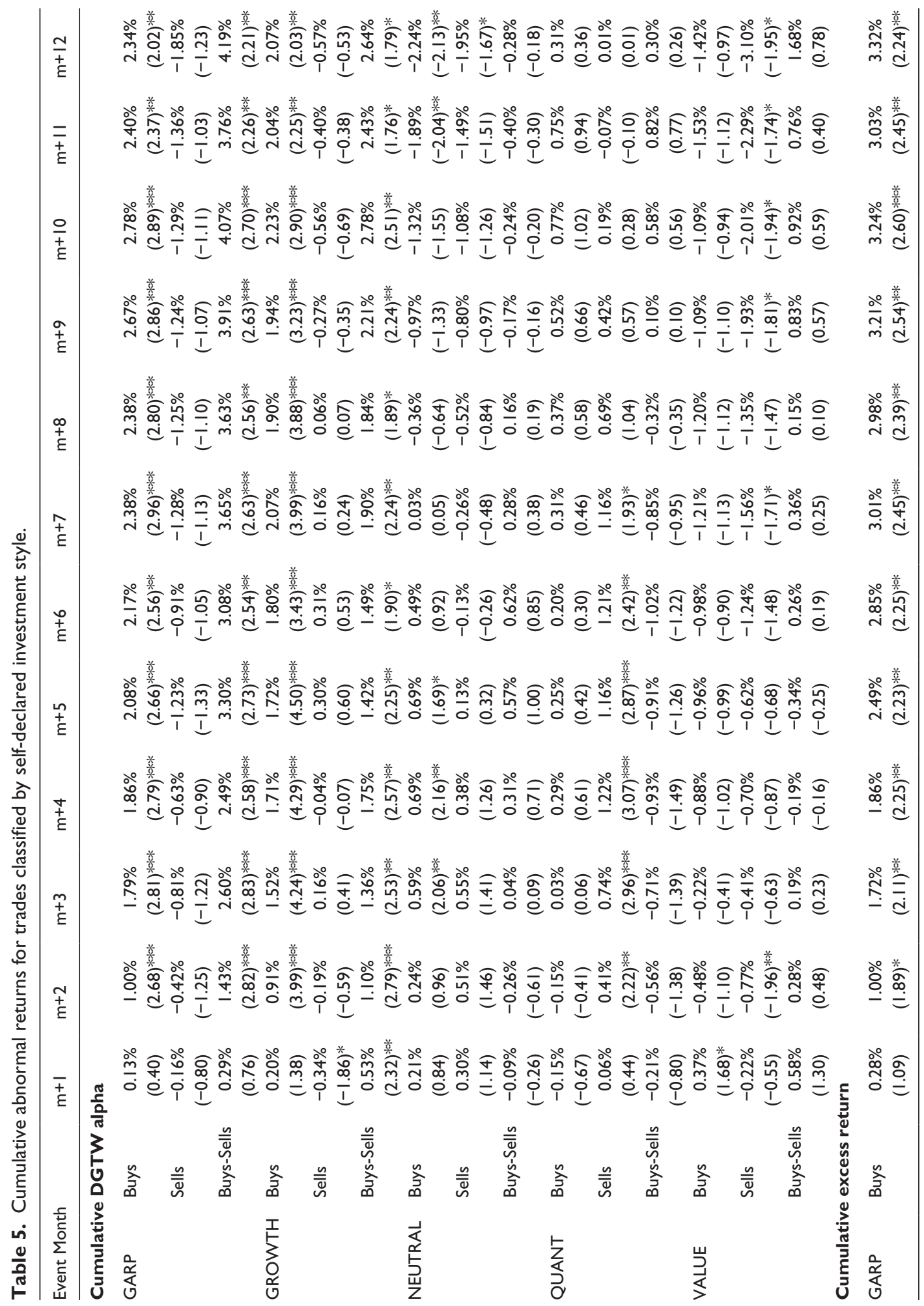




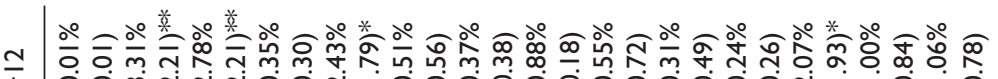
$\stackrel{+}{\stackrel{+}{\varepsilon}}$ $\stackrel{\overline{+}}{\overline{+}}$

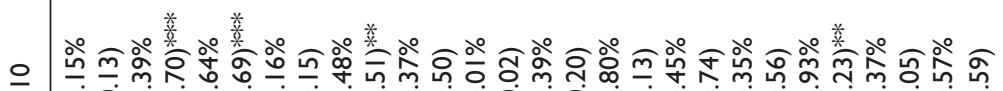
卉

\section{$\stackrel{+}{a}$}

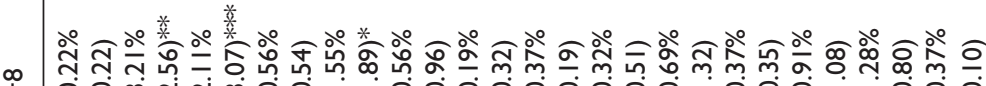

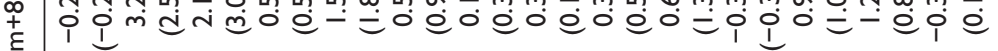

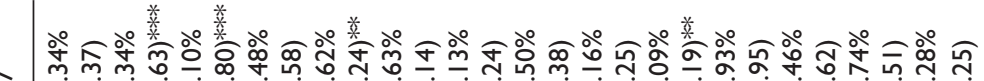
卉

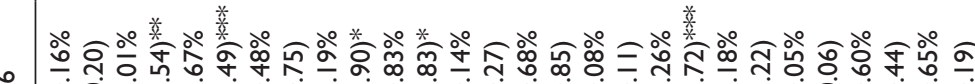
走 1 i m

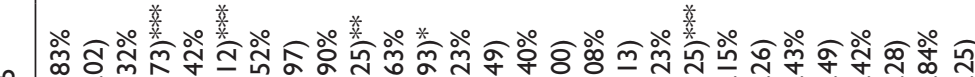
$\stackrel{+}{\varepsilon}$

\section{$\stackrel{+}{+}$}

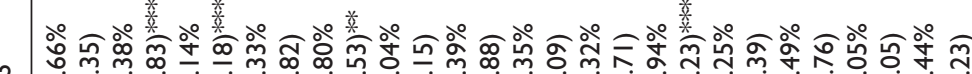
贲

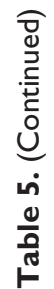

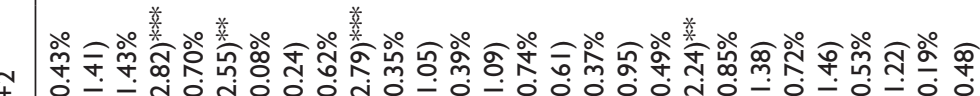
年

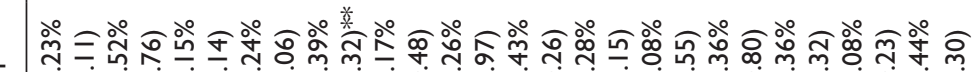

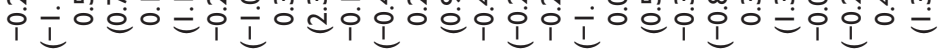

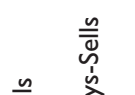

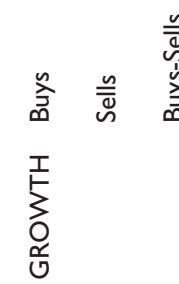

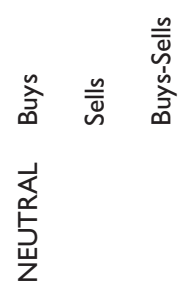

$\stackrel{n}{\bar{w}}$

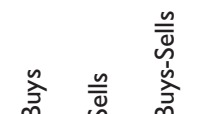

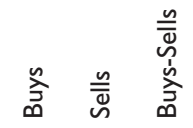

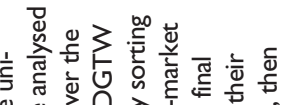

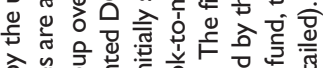

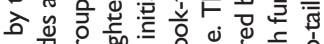

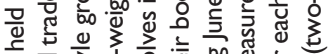

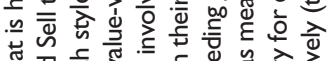

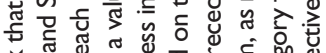
范合市

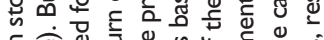

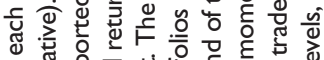

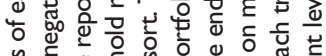

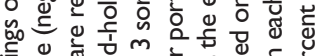

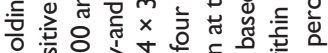

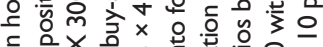

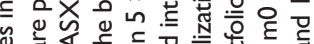

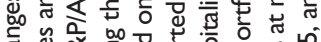

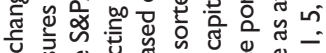

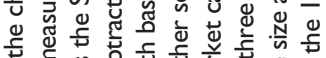

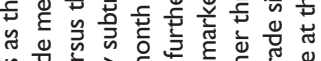

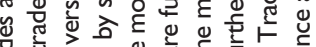

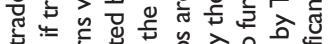

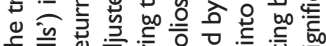

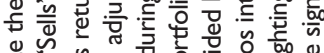

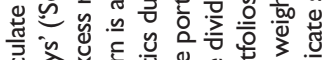

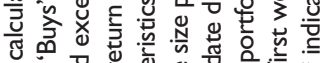

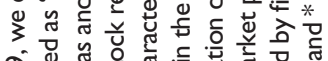

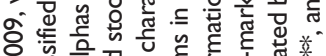
ठำ

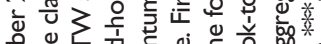
है

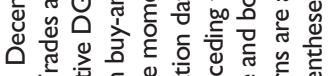

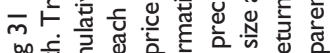

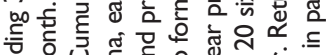

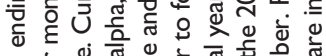

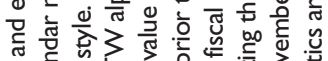

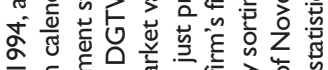

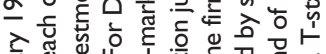

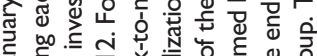

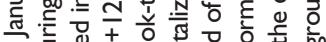

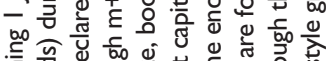

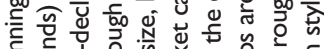

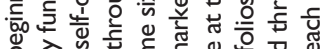

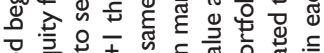

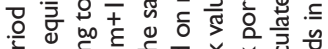

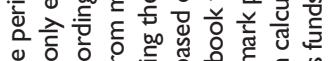
단

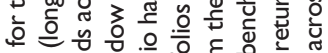

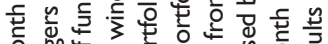

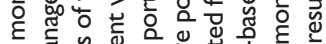

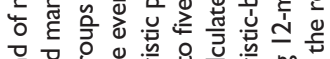

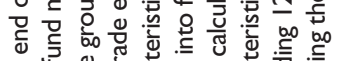

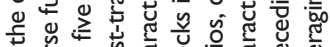

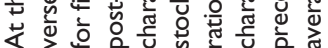




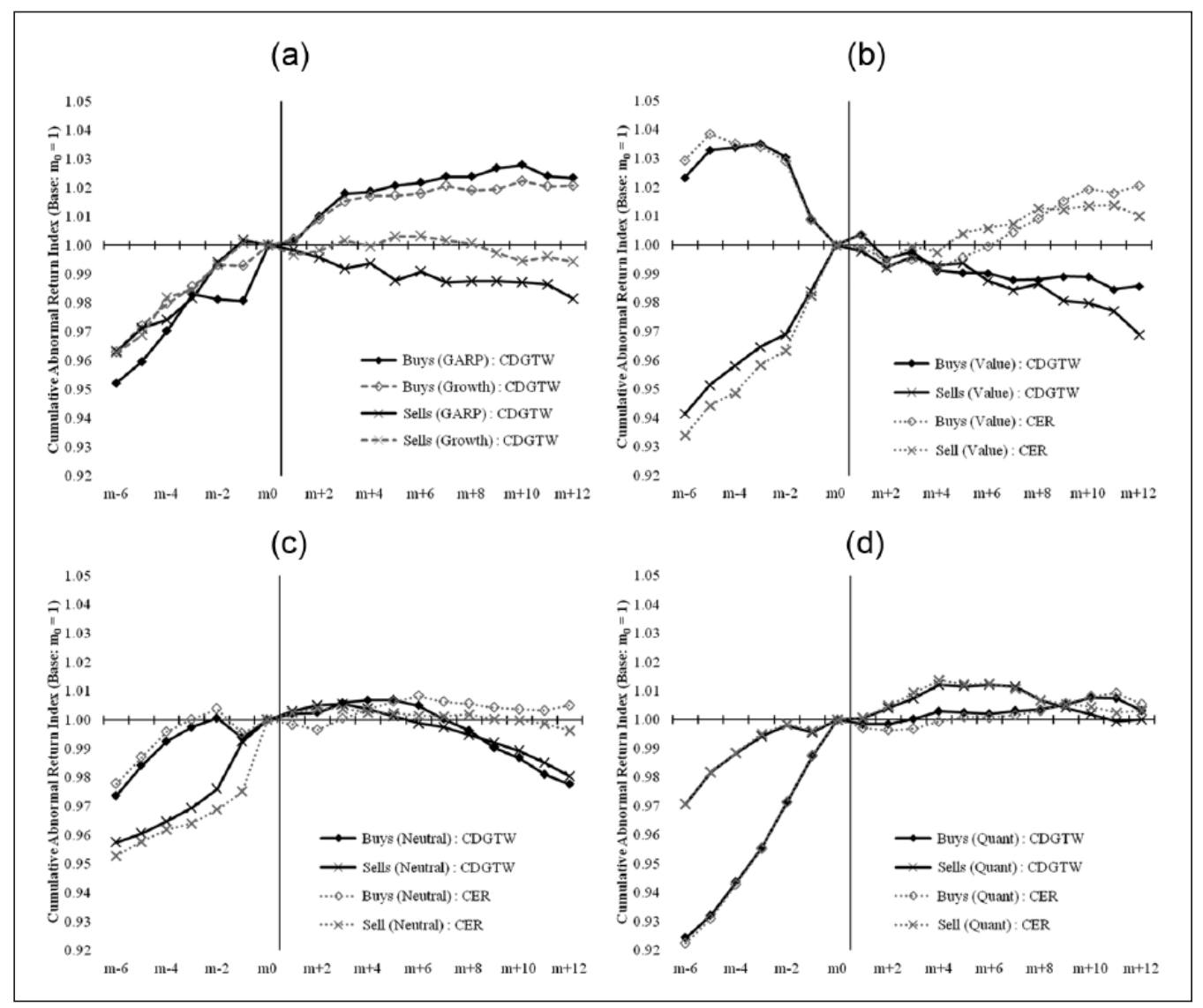

Figure 5. Selected indices of cumulative abnormal returns per fund style: (a) GARP and Growth funds, (b) Value funds, (c) Neutral funds and (d) Quant funds.

there is only patchy evidence of trading skill associated with other styles. Value and Neutral managers demonstrate Sell skill over the intermediate term, with negative CDGTW for their Sells reaching $-3.10 \%$ for Value and $-1.95 \%$ for Neutral in $m+12$. Both results are significant at the $10 \%$ level. On the other hand, their Buys generate negative CDGTW over the intermediate term after a period of shorter-term positive CDGTW, leaving the CDGTW Buy-Sell difference insignificant.

However, stark differences exist for Value (and to lesser extent Neutral) funds between DGTW alphas and excess returns. Buy CER for Value funds become positive after $m+6$, reaching a level of $+2.07 \%$ in $m+12$ (significant at the $10 \%$ level). By contrast, the equivalent CDGTW is $-1.42 \%$. Sells for Value funds show a similar but opposite pattern, with positive CER contrasting against negative CDGTW over the intermediate term. This suggests that a large portion of the excess returns for Value funds is sourced from exposure to characteristics rather than manager skill. The contrast between CDGTW and CER can be clearly seen in Figure 5(b) for Value funds, and Figure 5(c) for Neutral funds. For Quant managers, our analysis reveals no clear evidence of skill. The stocks traded by these funds generate negative CDGTW and CER Buy-Sell differences over the short-term horizon, which then become modestly positive after 8 months. The negative short-term 
performance for Quant funds can be traced to positive CDGTW and CER associated with Sells, which is also significant between $m+2$ and $m+7$.

Figure 5 provides insight into the trading patterns associated with the differing styles through plotting selected indices of cumulative abnormal return for Buys and Sells from $m-6$ to $m+12$. All styles with the exception of Value tend to trade in stocks that have outperformed, be it Buys or Sells. Buying stocks that have outperformed is consistent with momentum investing. However, selling stocks that have outperformed is more difficult to explain, and could reflect rebalancing following outperformance or perhaps a disposition effect where managers realize gains more readily than losses. In contrast, Value managers clearly adopt a contrarian strategy by buying stocks that have been posting negative abnormal returns and selling stocks that have outperformed.

One issue in interpreting the returns for Quant and Neutral funds is that these groups may contain a mixture of investment processes, given a large variation in approaches across constituents. This may be contributing to the mixed results, and makes it more difficult to generalize about their trading behaviour. Two additional issues exist for Quant funds. Russell Investments advises that Quant funds have a high average turnover rate of about $100 \%$, meaning that some may realize alphas within extremely short time horizons (perhaps less than 1 month, or even over a few days). Our monthly data may not be sufficiently granular to capture any value-add from frequent trading. In addition, Quant fund results may be heavily influenced by the experience during 2007-2009, when momentum factors underperformed. Meanwhile, styles like Value, which place more emphasis on investing over more extended time horizons, are better suited to analysis based on monthly data.

In summary, we find fund managers trade stocks in a manner that is broadly consistent with their investment styles. Growth-oriented funds demonstrate the best stock selection skill relative to other groups, with the largest portion of outperformance associated with their trades accruing over a short/intermediate-term horizon. Value funds typically adopt a contrarian strategy, and their performance tends to accrue over the intermediate term (after 4-6 months). Value manager returns appear to be driven by characteristic exposure rather than managerial skill. We find little evidence that Neutral and Quant funds have stock selection skill, although it is possible that skill may be partially obscured due to the blending of disparate investment processes into a single group and data difficulties with Quant funds.

\subsection{Performance of boutique versus institutional managers}

This section examines the role of differences in manager ownership and organization, specifically boutique versus institutional fund managers. Table 6 compares CDGTW for stocks traded by boutiques and institutional funds. CER results are very similar, and hence are not reported. In this sample, 57 out of 156 long-only equity funds are classified as boutiques by Russell Investments, or were classified as boutiques at some time during the period under analysis. Boutiques generate an additional $+0.63 \%$ of CDGTW alpha through to $m+12$. Outperformance is entirely driven by their Buys, which produce a significant additional $+1.57 \%$ in CDGTW by $m+10$ relative to institutional managers. In contrast, Sells of boutiques outperform the market but subtract from manager alpha (i.e. positive CDGTW for boutiques' Sells), while Sells of institutions underperform the market but add to manager alpha (i.e. mostly negative CDGTW for institutions' Sells, albeit insignificant). The gap in the CDGTW Buy-Sell difference peaks at $+0.97 \%$ in $m+10$ in favour of boutiques, although this is below significant levels. These results are consistent with the discussion in section 4.6, which identified a number of characteristics of boutiques that might facilitate outperformance, especially through their Buy decisions. 


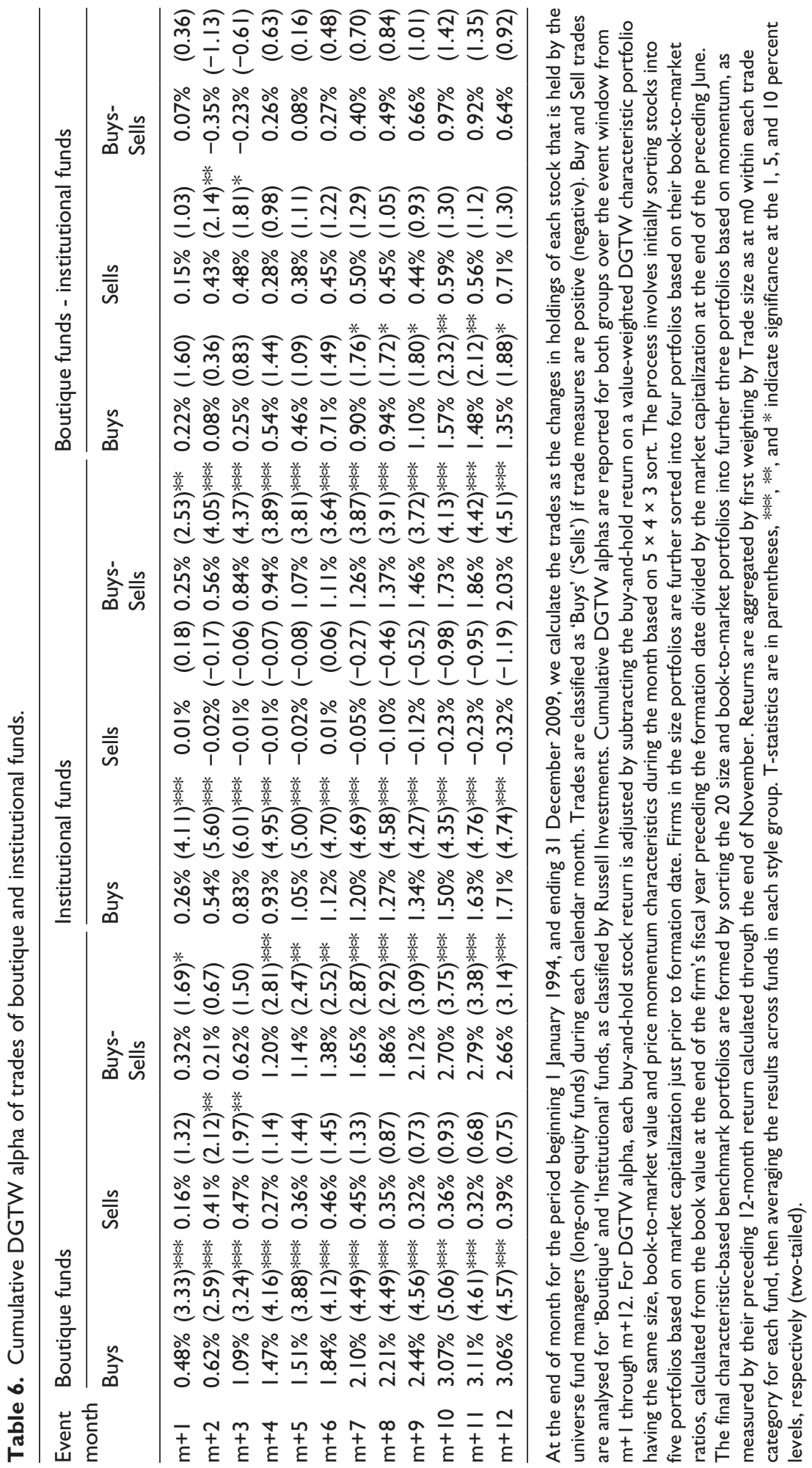




\section{Monthly versus quarterly net trades}

In this section we examine whether more frequent portfolio holdings data produces better performance inferences with respect to managerial skill. As discussed earlier, inferring trades from less frequent observations of portfolio holdings may downwardly bias the assessment of manager skill due to failure to observe intra-period transactions and lack of precision in estimating the timing of trades. Elton et al. (2011) suggest that employing quarterly holdings data misses $20 \%$ of the trades found in monthly data, and employing semi-annual data misses $34 \%$ of the trades. The benefit of using more frequent portfolio holdings data has been reinforced by Gallagher and Looi (2006) and Chen et al. (2010). Indeed, Puckett and Yan (2010) reveal that daily trade data versus quarterly inferred trades from holdings biases inferences of skill downward by between $0.20 \%$ and $0.26 \%$ per annum.

Table 7 reports return estimates inferred from quarterly portfolio holdings data, which are compared with their counterpart results based on monthly holdings. For our data, employing quarterly holdings data misses approximately $15 \%$ of the trades found in monthly data. Despite the majority of quarterly Buys being followed by significantly positive abnormal returns over $Q+1$ and $Q+2$, Buy-Sell differences are not generally statistically significant (with the exception of $Q+3$ for CER). Trades inferred from less frequent holdings also generate lower performance estimates. For example, the CDGTW (CER) Buy-Sell difference through to $Q+4$ is $0.40 \%(0.79 \%)$ using quarterly holdings. This is substantially lower than the counterpart estimated from monthly holdings of $1.41 \%(1.42 \%)$. These results are consistent with findings reported in Gallagher and Looi (2006), Chen et al. (2010) and Elton et al. (2011), confirming that less frequent holdings data is likely to attenuate performance and decrease precision in identifying the value of short-term information associated with manager trades.

\section{Conclusions}

This study investigates manager skill by examining net trades inferred from changes in aggregate portfolio holdings at the end of each month. Trade analysis is considered to be more powerful in identifying underlying stock selection ability relative to analysing portfolio holdings or realized fund-level returns, since managers will sometimes passively hold stocks for non-performance reasons, such as tracking error management, transaction cost minimization, mitigation of capital gains tax and portfolio diversification. This study uses the largest and most complete sample of fund holdings of active Australian equity managers to date, covering a total of 156 Australian active equity funds over the 16-year period from 1st January 1994 to 31st December 2009.

We uncover solid evidence of stock selection skill for Australian equity managers. This skill becomes most apparent when trades are categorized with a view to isolating trades with a higher probability of being motivated by information, rather than rebalancing or liquidity. Specifically, we focus on large trades, as well as trades where an overweight or underweight position is either being established or extended. Consistent with the existence of manager skill, the outperformance associated with trades is found to stem from these trade categories. Further, we analyse trades categorized by fund type. Categorizing by investment style indicates that Growth-oriented fund managers have superior trading skill relative to managers in other style groups. The trades of Value funds tend to outperform the index over the intermediate term, but this outperformance appears to be driven by exposure to characteristics other than stock selection skill. We also find that trades are aligned with self-declared investment style. Categorizing by entity type, we found that the trades of boutique funds generated greater abnormal returns than the trades of institutional funds, largely due to their Buy decisions. 


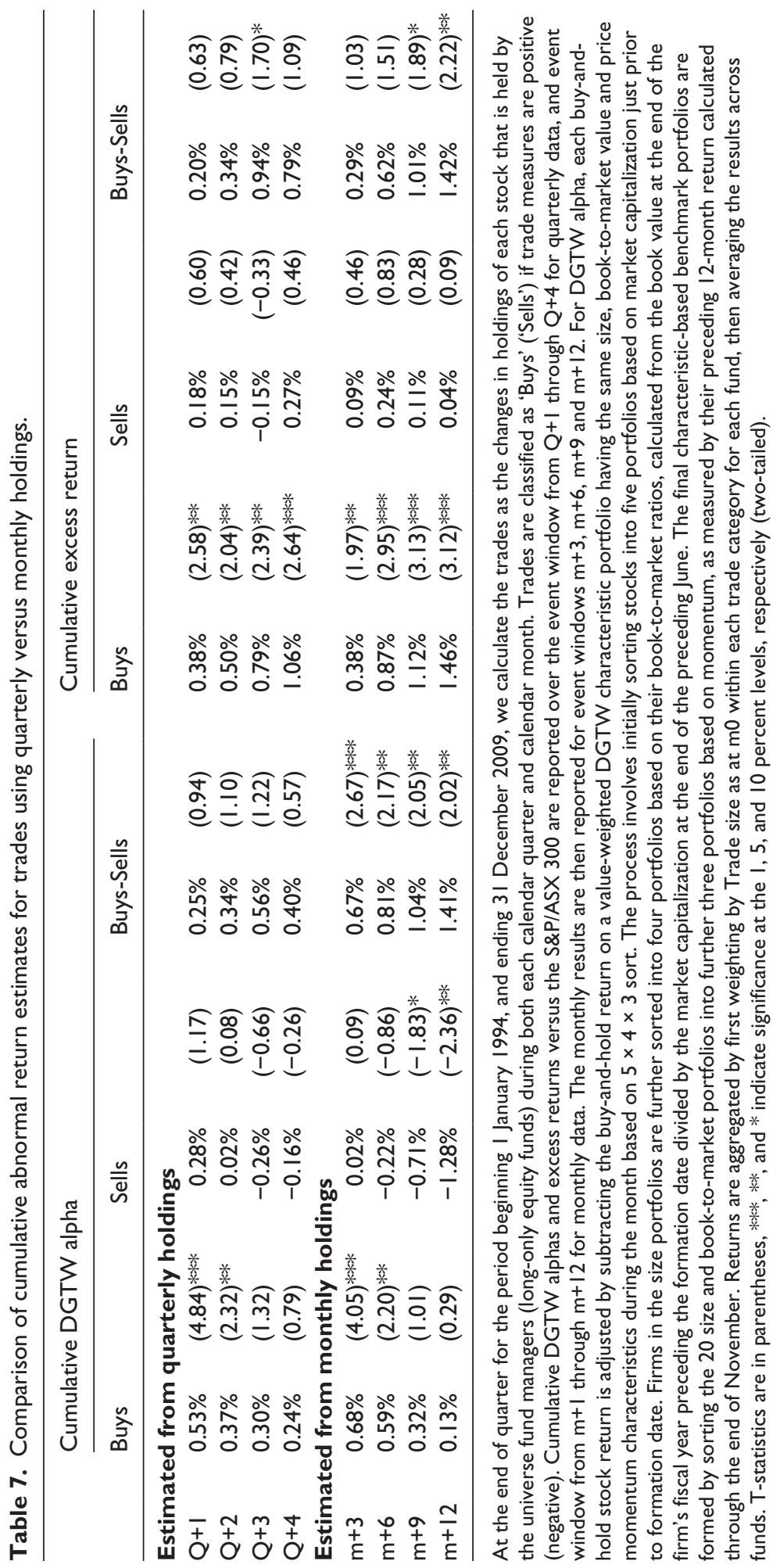


Lastly, comparing results using monthly and quarterly holdings data suggests that the latter substantially under-estimates performance. This confirms that trades inferred from less frequent holdings data lack the precision to accurately identify manager skill. In summary, our analysis provides confirmation that Australian equity managers possess skill, using a more comprehensive dataset than those that have been used in past studies. Further, by categorizing the data into sub-groups, we have been able to both identify this skill with greater precision, and better understand its sources.

\section{Acknowledgements}

The authors gratefully acknowledge the comments of an anonymous referee, the Editor (Karen Benson), and research funding by the Capital Markets CRC Limited and Russell Investments. We thank seminar participants at the University of Technology, Sydney, and Macquarie University for helpful comments and suggestions. We also thank Tim Gapes, as well as Russell Investments for access to their data and contributions from their employees, especially James McSkimming.

\section{Funding}

This research was funded by Capital Markets CRC Limited and sponsored by Russell Investments.

\section{Notes}

1. For instance, US studies such as Chen et al. (2000) and Kacperczyk et al. (2005) find strong evidence of stock-picking skill from Buy only.

2. In addition there is some empirical research focusing on individual transactions of investment managers, analysing the price impact and transaction costs of these trades (see Keim and Madhavan (1996), Petersen and Umlauf (1991), Hausman et al. (1992) and Chan and Lakonishok (1993)).

3. Duan et al. (2009) define idiosyncratic volatility as firm-specific information volatile in nature. It is measured by standard deviation of monthly returns that is orthogonal to the market, and standard deviation of monthly returns that is orthogonal to the Fama-French-Carhart four-factor model.

4. GARP funds tend to favour stocks with growth attributes, but also consider valuations.

5. Quant funds are funds that use quantitative research and computer models to select securities.

6. Russell Investments obtains fund style information through on-site, in-depth, face-to-face interviews with portfolio managers.

7. AGSM (SPPR) database stands for the Share Price and Price Relative database of the Australian Graduate School of Management. The AGSM operates as part of the Australian School of Business at UNSW Australia.

8. Aggregate market value relates to fund holdings included in the sample, and does not represent the total Funds Under Management for our sample of funds.

9. We also further partition the monthly net return data into five time periods of 1994-1997, 1997-2000, 2000-2003, 2003-2006 and 2006-2009. We find the difference in performance to be positive in all subperiods but significant only during 2003-2006 associated with a market upturn.

10. Where holdings data is complete and there are no cash flows, our imputed trade measure should equate to actual net trades over the period. Under these circumstances, the portfolio is a closed system where each purchase or sale must have a counterpart in either another trade or change in cash weight.

11. For example, if cash inflows were entirely invested in one stock, then its weighting would rise and the weighting of all other stocks would decline. Hence an imputed trade will be recorded under our method for all stocks in the portfolio, although a physical trade occurs in only one stock.

12. Market index prior to April 2000 is the ASX All Ordinaries Index.

13. Daniel et al. (1997).

14. To construct DGTW benchmark portfolios, we use AGSM universe stocks with data available for book equity values, stocks returns and market capitalization.

15. Although the magnitude of results for the alternative DGTW alpha measures sometimes differed, the 
overall conclusions were unchanged.

16. It is more likely that Sell trades when an underweight exists could be rebalancing trades. This reflects the fact that if a stock held underweight underperforms the market, revaluation effects will decrease the magnitude of the underweighting. The manager may then need to sell additional stock if they are managing towards a target level of underweighting.

17. Our characterization of boutiques relies on observations made by Russell Investments, which monitors and researches active managers as part of its business. Boutiques have become an increasingly important type of fund manager in the Australian marketplace, particularly during our sample period. There are many organizations in Australia that offer services to new entrants to assist in the incubation and establishment of boutique investment operations.

18. Methods used by Russell Investments to identify fund type were described in section 3 .

19. Kyle (1985), Easley and O'Hara (1987), and Holthausen et al. (1987)

20. Saar (2001), Chan and Lakonishok (1993), Keim and Madhavan (1996) and Pinnuck (2003).

21. Significantly negative CDGTW are associated with 'pre over, post zero' for $m+1$ only; and 'pre over, post under' for $m+10$ and $m+11$ only.

22. The manager remains overweight, and may be reducing what has been a successful overweighting that has been enlarged by revaluation effects.

\section{References}

Ainsworth A, Gallagher DR and Gardner P (2007) Performance evaluation and the potential biases in fund manager return databases. JASSA 2: 21-27.

Alexander GJ, Cici G and Gibson S (2007) Does motivation matter when assessing trade performance? An analysis of mutual funds. Review of Financial Studies 20: 125-150.

Algert PM (1990) Estimates of Non-Linearity in the Response of Stock Prices to Order Imbalances. Mimeo University of California, Berkeley.

Baker M, Litov L, Wachter J, et al. (2010) Can mutual fund managers pick stocks? Evidence from their trades prior to earnings announcements. Journal of Financial and Quantitative Analysis 45: $1111-1131$.

Barberis N and Shleifer A (2003) Style investing. Journal of Financial Economics 68: 161-199.

Barclay MJ, Dunbar CG and Warner JB (1993) Stealth and volatility: Which trades move prices? Journal of Finance 34: 75-84.

Barras L, Scaillet O and Wermers R (2010) False discoveries in mutual fund performance: Measuring luck in estimated alphas. Journal of Finance 65: 179-216.

Bennett JA, Sias RW and Starks LT (2003) Greener pastures and the impact of dynamic institutional preferences. Review of Financial Studies 16: 1203-1238.

Berk JB and Green RC (2004) Mutual fund flows and performance in rational markets. Journal of Political Economy 112: 1269-1295.

Brands S, Brown S and Gallagher DR (2005) Portfolio concentration and investment manager performance. International Review of Finance 5: 149-174.

Cai F and Zheng L (2004) Institutional trading and stock returns. Finance Research Letters 1: 178-189.

Chan KC, Chen HL and Lakonishok J (2002) On mutual fund investment styles. Review of Financial Studies 15: $1407-1437$.

Chan LK and Lakonishok J (1993) Institutional trades and intra-day stock price behaviour. Journal of Financial Economics 33: 173-199.

Chen C, Comerton-Forde C, Gallagher DR, et al. (2010) Investment manager skill in small-cap equities. Australian Journal of Management 35: 23-49.

Chen H, Jegadeesh N and Wermers R (2000) The value of active mutual fund management: An examination of the stockholdings and trades of fund managers. Journal of Financial and Quantitative Analysis 35: 343-368. 
Christoffersen SE, Keim DB and Musto DK (2007) Valuable Information and Costly Liquidity: Evidence from Individual Mutual Fund Trades (working paper). Montréal, QC, Canada: McGill University, Charlottesville, VA: University of Virginia and Philadelphia, PA: University of Pennsylvania.

Cremers KJM and Petajisto A (2009) How active is your fund manager? A new measure that predicts performance. Review of Financial Studies 22: 3329-3365.

Daniel K, Grinblatt M, Titman S, et al. (1997) Measuring mutual fund performance with characteristic-based benchmarks. Journal of Finance 52: 1035-1058.

Duan Y, Hu G and McLean RD (2009) When is stock picking likely to be successful? Evidence from mutual funds. Financial Analysts Journal 65: 55-65.

Easley D and O'Hara M (1987) Price, trade size, and information in securities markets. Journal of Financial Economics 19: 69-90.

Easley D, Kiefer NM and O'Hara M (1997) The information content of the trading process. Journal of Empirical Finance 4: 159-186.

Elton EJ, Gruber MJ and Blake CR (1996) The persistence of risk-adjusted mutual fund performance. Journal of Business 69: 133-157.

Elton EJ, Gruber MJ and Blake CR (2011) Holding data, security returns, and the selection of superior mutual funds. Journal of Financial and Quantitative Analysis 46: 341-367.

Elton EJ, Gruber MJ, Blake CR, et al. (2010) The effect of holdings data frequency on conclusions about mutual fund management behaviour. Journal of Banking and Finance 34: 912-922.

Fama EF and French KR (2010) Luck versus skill in the cross section of mutual fund returns. Journal of Finance 65: 1915-1947.

Fong K, Gallagher DR and Lee AD (2007) Measuring Characteristic Selectivity and Timing Ability Using Equity Portfolio Holdings (working paper). Sydney, NSW, Australia: University of New South Wales.

Foster FD, Gallagher DR and Looi A (2011) Institutional trading and share returns. Journal of Banking and Finance 35: 3383-3399.

Gallagher DR and Looi A (2006) Trading behaviour and the performance of daily institutional trades. Accounting and Finance 46: 125-147.

Grinblatt M and Titman S (1989) Mutual fund performance: An analysis of quarterly portfolio holdings. Journal of Business 62: 393-416.

Grinblatt M and Titman S (1993) Performance measurement without benchmarks: An examination of mutual fund returns. Journal of Business 66: 47-68.

Hasbrouck J (1988) Trades, quotes, inventories and information. Journal of Financial Economics 22: 229252.

Hasbrouck J (1991) Measuring the information content of stock trades. Journal of Finance 46: 179-207.

Hausman J, Lo A and MacKinlay C (1992) An ordered probit analysis of transaction stock prices. Journal of Financial Economics 31: 319-379.

Holthausen RW, Leftwich RW and Mayers D (1987) The effect of large block transactions on security prices: A cross-sectional analysis. Journal of Financial Economics 19: 237-268.

Iihara Y, Kato H and Tokunaga R (2004) The winner-loser effect in Japanese stock returns. Japan and the World Economy 16: 471-485.

Kacperczyk M, Sialm C and Zheng L (2005) On the industry concentration of actively managed equity mutual funds. Journal of Finance 60: 1983-2011.

Kacperczyk M, Sialm C and Zheng L (2008) Unobserved actions of mutual funds. Review of Financial Studies 604: 2379-2416.

Keim D and Madhavan A (1996) The upstairs market for large-block transactions: Analysis and measurement of price effects. Review of Financial Studies 9: 1-36.

Kothari SP and Warner JB (2001) Evaluating mutual fund performance. Journal of Finance 56: 1985-2010.

Kyle A (1985) Continuous auctions and insider trading. Econometrica 53: 1315-1335.

Madhavan A and Smidt S (1991) A Bayesian model of intraday specialist pricing. Journal of Financial Economics 30: 99-134. 
Pastor L and Stambaugh RF (2002a) Investing in equity mutual funds. Journal of Financial Economics 63: 351-380.

Pastor L and Stambaugh RF (2002b) Mutual fund performance and seemingly unrelated assets. Journal of Financial Economics 63: 315-349.

Petersen M and Umlauf S (1991) An Empirical Examination of the Intraday Behaviour of the NYSE Specialist (working paper). Chicago, IL: University of Chicago.

Pinnuck M (2003) An examination of the performance of the trades and stock holdings of fund managers: Further evidence. Journal of Financial and Quantitative Analysis 38: 811-828.

Puckett A and Yan XM (2010) Short-Term Institutional Herding and Its Impact on Stock Prices (working paper). Knoxville, TN: University of Tennessee.

Saar G (2001) Price impact asymmetry of block trades: An institutional trading explanation. Review of Financial Studies 14: 1153-1181.

Schultz P (2010) Rational cross-sectional differences in market efficiency: Evidence from mutual fund returns. Journal of Financial and Quantitative Analysis 45: 847-881.

Wermers R (1999) Mutual fund herding and the impact on stock prices. Journal of Finance 53: 581-622.

Wermers R (2000) Mutual fund performance: An empirical decomposition into stock-picking talent, style, transactions costs and expenses. Journal of Finance 55: 1655-1695.

Wylie S (2005) Fund manager herding: A test of the accuracy of empirical results using U.K. Data. Journal of Business 78: 381-403.

Yan XM and Zhang Z (2009) Institutional investors and equity returns: Are short-term institutions better informed? Review of Financial Studies 22: 893-924. 